\title{
ACCURATE COMPUTATION OF A STREAMFLOW DROUGHT INDEX
}

Sergio M. Vicente-Serrano ${ }^{1}$, Juan I. López-Moreno ${ }^{1}$, Santiago Beguería ${ }^{2}$, Jorge Lorenzo-Lacruz ${ }^{1}$, Cesar Azorin-Molina ${ }^{1}$ and Enrique Morán-Tejeda ${ }^{1}$

1) Instituto Pirenaico de Ecología, CSIC (Spanish National Research Council), Campus de Aula Dei, P.O. Box 202, Zaragoza 50080, Spain

2) Estación Experimental de Aula Dei CSIC (Spanish National Research Council), Zaragoza, Spain.

\footnotetext{
*svicen@ipe.csic.es
}

\begin{abstract}
In this study we investigated an approach to the calculation of a Standardized Streamflow Index (SSI) that allows accurate spatial and temporal comparison of the hydrological conditions of a stream or set of streams. For this purpose the capability of six three-parameter distributions (lognormal, Pearson type III, log-logistic, General Extreme Value, Generalized Pareto and Weibull) and two different approaches to select the most suitable distribution: the Best Monthly Fit (BMF) and the Minimum orthogonal Distance (MD), was tested using a monthly streamflow dataset for the Ebro basin (Spain). This large Mediterranean basin is characterized by high variability in the magnitude of streamflows and in seasonal regimes. The results show that the most commonly used probability distributions for flow frequency analysis provided good fits to the streamflow series. Thus, visual inspection of the L-moment diagrams and the results of the Kolmogorov-Smirnov test did not enable selection of a single optimum probability distribution. However, no single probability distribution for all the series was suitable for obtaining a robust standardized streamflow series, as each of the distributions had one or more limitations. The BMF and MD approaches provided improved results in terms of the expected average, standard deviation and frequencies of extreme events of the SSI
\end{abstract}


series in relation to the selection of a unique distribution for each station. The BMF and MD approaches involved using different probability distributions for each gauging station and month of the year to calculate the SSI. Both approaches are easy to apply and they provide very similar results in terms of the quality of the obtained hydrological drought indices. The proposed procedures are very flexible for analyses involving contrasting hydrological regimes and flow characteristics.

Keywords: hydrological drought, river flows, Standardized Streamflow Index, Standardized Precipitation Index, low flows, runoff index, flow index

\section{Introduction}

Drought is one of the greatest natural hazards, with effects on many sectors and systems, and major impacts on agriculture, water resources and natural ecosystems. Droughts affect many people worldwide, are responsible for famine, epidemics and land degradation in developing countries (Obasi, 1994; Nicholson, 2001), and cause large economic losses in developed regions (Meehl et al., 2000; Fink et al., 2004; UN, 2008).

Drought is a natural phenomenon that occurs when water availability is significantly below normal levels over a long period, and cannot meet demand (Havens, 1954; Redmond, 2002). Drought conditions are much more difficult to identify than other natural hazards because drought is commonly the result of a number of factors that are only apparent after a long period of precipitation deficit. Consequently, it is very difficult to determine the onset, extent and end of droughts (Wilhite, 1993). In contrast to other natural hazards including floods, which are typically restricted to small regions and occur over well defined temporal intervals, drought is difficult to pinpoint in time and space because it affects wide areas over long time periods. Moreover, it is very difficult to 
objectively quantify drought severity, which is a combination of the duration, magnitude and spatial extent of a drought (Dracup et al., 1980).

Much effort has been devoted to developing robust approaches to the calculation of climate drought indices (see review in Heim, 2002), as they provide the potential to accurately quantify the severity of droughts in terms of magnitude, duration and spatial extent. A key feature of drought indices is that they must enable the severity of droughts in different locations to be compared independently of the local climatic characteristics. Thus, the procedures for quantifying climate drought conditions are commonly based on the calculation of standardized series $(z$-scores, with an average $=0$ and a standard deviation $=1$ ) from the magnitudes of hydroclimatic variables of interest, which include precipitation and water balances. This enables the relative severity of water deficits to be determined independently of the seasonal and spatial characteristics of the variable.

Following this approach, a climate drought index can be obtained from long time series using the cumulative distribution function corresponding to each value $i_{t}$ of the hydroclimatic variable of interest. This is commonly obtained using the probability distribution that shows the best fit to the data. For example, calculation of the Standardized Precipitation Index (SPI; McKee et al., 1993), which is one of the most commonly used climate drought indices, is based on the Gamma (McKee et al., 1993) or the Pearson type III distribution (Guttman, 1999; Vicente-Serrano, 2006), while calculation of the Standardized Precipitation Evapotranspiration Index (SPEI) is based on the loglogistic distribution (Vicente-Serrano et al., 2010). Several studies have shown the ability of these distributions to fit time series of precipitation and water balance over a wide range of climate regions (Guttman, 1999; Vicente-Serrano et al., 2010b).

Hydrological drought refers to a decrease in surface or ground water resources, commonly river flows, reservoir storages and aquifers (Tallaksen and Van Lanen, 2004). Hydrological droughts can have widespread impacts by reducing or eliminating water supplies, deteriorating water quality, restricting water for irrigation and causing crop failure, reducing power generation, disturbing 
riparian habitats, limiting recreation activities, and affecting a diversity of economic and social activities (Mishra and Singh, 2010). Although the origin of hydrological droughts is commonly climate droughts (Zaidman et al., 2001; Hisdal and Tallaksen, 2003; Beersma and Buishand, 2004; Vasiliades and Loukas, 2009; Edossa et al., 2010; Hannaford et al., 2010; Lorenzo-Lacruz et al., 2010; Vidal et al., 2010), the quantification of hydrological droughts as independent phenomena has also received much attention in the scientific community. This is because there are not usually direct spatial or temporal relationships between the occurrence of climate and hydrological droughts (Vicente-Serrano and López-Moreno, 2005; Tallaksen et al., 2009; Hannaford et al., 2010; LorenzoLacruz et al., 2010; Vidal et al., 2010). Moreover, analysis of hydrological droughts allows direct quantification of the deficits in usable water sources.

In contrast to climate droughts, the quantification of hydrological droughts is not usually based on indices, but on the theory of runs (Yevjevich, 1967). A drought event is defined as the period during which the hydrological variable is below a predetermined truncation level. Following this approach, the duration of drought is the time when with streamflow is below the truncation level, and drought severity is the cumulative deviation below the truncation level during that period. Therefore, selection of the truncation level is critical in defining a drought, and can be based on the average of a series (Dracup et al., 1980), a percentile (Zelenhasic and Salvai, 1987), or relative values with respect to the average (Clausen and Pearson, 1995). Some studies have improved the identification of droughts by considering the mutual dependence among drought events (Tallaksen et al., 1997; Fleig et al., 2006). This approach has the advantage of considering the real low-flow periods, during which the availability of water is unable to meet demand, with consequent environmental and socioeconomic impacts (Smakhtin, 2001). Nevertheless, given the contrasting river regimes and flow magnitudes that can occur among neighboring basins, the spatial comparison of drought severity and the development of drought maps are not possible using the method of runs. This is because the same drought magnitude may have different implications, according to the basin. In addition, the 
seasonality of river flows must be taken into account in quantifying hydrological droughts. In rivers with high seasonality, the low flow periods usually correspond to reduced water availability in summer. Nevertheless, a reduction in discharges during high flow periods can also have negative impacts on natural systems adapted to a particular river regime. Thus, relatively low flows during high flow periods can reduce reservoir storages downstream, affecting the availability of water resources for certain uses some months later. For these reasons, in addition to low-flow analysis based on the run theory (see reviews in: Smakhtin, 2001; Tallaksen and Van Lanen, 2004), it would be advantageous to develop a standardized hydrological drought indicator that allows comparisons of drought severity across time and space, including in basins with different characteristics in terms of regimes, flow variability and the magnitude of flows. Such an indicator could be implemented following the same theoretical approach used for the calculation of climate drought indices.

Stahl (2001) developed the Regional Deficiency Index (RDI) to characterize hydrological droughts. The RDI is based on daily flow data, and removes the influence of streamflow seasonality on droughts. Nevertheless, the index does not indicate the magnitude of a drought (it only quantifies the duration from a binary time series), and drought severity is quantified in terms of the surface affected, which makes comparisons of hydrological droughts at different stations impossible.

Two hydrological drought indices have recently been developed following the approach commonly used for climate drought indices: these are the Streamflow Drought Index (Nabaltis and Tsakiris, 2009) and the Standardized Runoff Index (Shukla and Wood, 2008). These indices have the same theoretical background because they derive the hydrological drought index by transformation of monthly streamflows into $z$-scores. The problem in this approach is that selection of the most suitable probability distribution to calculate the index, and the consequences of the selection on the final series have not been tested in depth. In development of the SPI, various probability distributions were carefully tested to select the most suitable (McKee et al., 1993; Guttman, 1999). The same approach was followed in development of the SPEI (Vicente-Serrano et al., 2010). These 
studies provided evidence about the suitability of the Pearson type III and log-logistic distributions to fit precipitation and water balance series, respectively, across a wide range of climate regimes and time scales.

Streamflow commonly shows greater spatial variability than the climatic variables used to derive drought indicators. This is because of the influence of a number of factors including topography, lithology, vegetation and human management, but also as a consequence of the spatial aggregation of the flows, which changes the statistical properties of the series downstream (Mudelsee, 2007). Therefore, a high degree of spatial variability occurs in the probability distributions that best fit the monthly streamflow data (Riggs, 1973; Kroll and Vogel, 2002; Yue and Wang, 2004; Yue and Pilon, 2005; McMahon et al., 2007; Yue and Hashino, 2007), which makes it difficult to select the most appropriate distribution to calculate a streamflow drought index over a wide area.

In this study we tested the performance of several probability distributions, assuming that each month may fit to different probability distributions, for use in calculating a Standardized Streamflow Index (SSI). This has enabled us to propose an accurate procedure for obtaining a hydrological drought index that is useful for making spatial and temporal comparisons over a wide variety of river regimes and flow characteristics.

\section{Methods}

\subsection{Data set}

We used the Ebro River basin (northeast Spain) for calculating and testing the performance of the SSI. This basin is characterized by large spatial variability in the river regimes and flow magnitudes. The Ebro basin is the largest in Spain (surface area $85,362 \mathrm{Km}^{2}$ ) and covers $17.3 \%$ of the country. The Ebro River flows from the Cantabrian Range to the Mediterranean Sea; it is the main river in the 
Ebro basin, with a total length of $910 \mathrm{~km}$. The basin is bounded to the north by the Cantabrian Range and the Pyrenees, which have maximum altitudes of more than $3000 \mathrm{~m}$ asl, and the Iberian Mountains (maximum altitudes 2000-2300 m asl) enclose the Ebro basin to the south. The heterogeneous topography and contrasting Atlantic and Mediterranean influences generate a complex spatial distribution of climate parameters, and large variations in precipitation and evapotranspiration throughout the region (Cuadrat et al., 2007; Vicente-Serrano et al., 2007). Thus, the annual precipitation varies from 307 to $2451 \mathrm{~mm} \mathrm{yr}^{-1}$; most falls in autumn and spring (Cuadrat et al., 2007), although in some areas the maximum precipitation occurs in winter and summer (Beguería et al., 2009). The average annual temperature varies from 0.8 to $16.2^{\circ} \mathrm{C}$.

The marked differences in topographic and climatic conditions explain the high variability of river flows and regimes. In the headwaters in the Pyrenees and the Iberian Range the rivers are snow-fed, with flow regimes characterized by marked seasonality. The mid courses of the rivers are also subject to large seasonal variability that is driven by dry summers, and high flow episodes are common in winter and autumn in response to extreme precipitation events (Ollero et al., 2004). The basin is highly regulated, with 126 reservoirs currently active; these manage the water resources for hydropower production, irrigation and urban consumption. Most of the dams were built between the $1950 \mathrm{~s}$ and the $1980 \mathrm{~s}$, and their construction increased the storage capacity from 500 to $6500 \mathrm{Hm}^{3}$, which represents $50 \%$ of the average annual outflow to the Mediterranean Sea (1945-2005 average: $\left.12208 \mathrm{Hm}^{3}\right)$.

The hydrological records used in this study were provided by the Ebro Water Management Agency (Confederación Hidrográfica del Ebro). We used monthly streamflow data from 98 of 420 gauging stations located across the basin; the data covered the period 1945-2005. Selection of the data series was based on the criterion that gaps resulting from missing data should not represent more than $10 \%$ of the total length of the series. Gaps were filled by multiple linear regression using highly correlated stations located on the same river or in very close proximity (Hirsch, 1982; Vogel and Stedinger, 
1985). Thus, the objective series had a Pearson's correlation coefficient of at least $R=0.8$. Figure 1 shows the spatial distribution of the selected stations.

\subsection{Calculation of the SSI}

Various probability distributions have been used to obtain hydrological drought indices. A unique probability distribution is usually selected to fit all the available series and/or variables. For example, Zaidman et al. (2001) used the log-normal distribution to fit river flow series for the period 1960-1995 for 2781 stations from sites in the UK, Ireland, France, Germany, the Netherlands, Belgium, Denmark, Switzerland, Austria and the Czech Republic. The same distribution was used by Nalbantis and Tsakiris (2009) in the Evinos basin (Greece). Other authors have assessed the performance of various distributions used to derive hydrological drought indices. López-Moreno et al. (2009) and Lorenzo-Lacruz et al. (2001) used the Pearson type III distribution to fit monthly streamflow series in the central Iberian Peninsula. The same distribution was used by Mo (2008) to obtain standardized runoff series in the USA. However, Shukla and Wood (2008) noted the role of varying hydroclimatic regimes in the USA in relation to selection of the best probability distribution for adjusting the data, and reported that the 2-parameter Gamma and log-normal distributions generally performed well, but also showed that the 3-parameter log-normal and the Generalized Extreme Value distributions were also applicable.

Some studies have shown that the regionalization of river flows can be established according to a particular probability distribution, with the potential to apply common parameters to the various runoff series (Hosking and Wallis, 1993; Bobee et al., 1996; Burn, 1997; Yue and Wang, 2004; Modarres and Sarhadi, 2010; Shi et al., 2010). Nevertheless, the use of a unique probability distribution function for different river sectors and months requires high spatial homogeneity among the series, which is unlikely to be found in rivers with physical characteristics, climatic, hydrological 
regimes and hierarchy that differ, even over very short distances. Therefore, it can be assumed that the most suitable probability distribution to fit individual streamflow series will vary. Similarly, large seasonal variations in streamflow characteristics can cause differences in the twelve monthly series at a single station. For example, Figure 2 shows the frequency histograms of the streamflow series for January, March and May at the Sástago station in the Ebro River. The theoretical probability distributions that show the best fit to the data are also indicated in Figure 2. This example illustrates how the fitting of monthly runoff series from the same location to different distributions can affect the procedure for calculating hydrological drought indices.

In this study we applied two approaches to the use of probability distributions to obtain a Standardized Streamflow Index.

\subsubsection{Using a unique distribution of probability}

In the first approach we used a unique probability distribution to fit the monthly streamflow series with independent fitted parameters at each site and month. We selected six 3-parameter distributions widely used in hydrological analysis (Chow et al., 1988; Bobée and Ashkar, 1991; Vogel et al., 1993; Rao and Hamed, 2000): the General Extreme Value (GEV), Pearson type III (PIII), loglogistic, log-normal, Generalized Pareto and Weibull distributions. For example, Figure 3 shows the May series for the Sástago station (Ebro River) with the six theoretical distributions that fit the data. The flexibility of having a wide range of distributional shapes given the three-parameters of the distributions allows a good fit to the observed frequencies. Therefore, for each streamflow series we calculated six SSI series, corresponding to each of the six probability distributions used.

Table 1 shows $F(x)$ (the cumulative distribution function) for each of the six selected distributions. The calculation of $F(x)$ is essential to obtaining the SSI. The table includes the equations used to calculate the parameters of the six probability distributions; these were based on the L-moment 
method (see below). Once $F(x)$ is calculated the SSI (in $z$-scores) can easily be determined following (for example) the classical approximation of Abramowitz and Stegun (1965):

$S S I=W-\frac{C_{0}+C_{1} W+C_{2} W^{2}}{1+d_{1} W+d_{2} W^{2}+d_{3} W^{3}}$,

where

$W=\sqrt{-2 \ln (P)}$ for $P \leq 0.5$,

$P$ is the probability of exceeding a determined $x$ value, and $P=1-F(x)$. If $P>0.5, P$ is replaced by $1-P$ and the sign of the resultant SSI is reversed. The constants are: $C_{0}=2.515517, C_{1}=0.802853$, $C_{2}=0.010328, d_{1}=1.432788, d_{2}=0.189269, d_{3}=0.001308$. If the probability distribution is suitable for fitting the monthly streamflow series, the average value of the SSI and the standard deviation must equal 0 and 1, respectively. The SSI is a standardized variable, and can therefore be compared with other SSI values across time and space.

\subsubsection{Using different distributions for each monthly series}

The second approach was based on selection of the most suitable probability distribution for each monthly streamflow series. Using this approach a SSI was created for each monthly streamflow series, whereby the twelve monthly streamflow series could be fitted by different probability distributions. To select the most suitable distribution for each series we tested the capability of two different approaches:

1. The selection of the most suitable distribution according to L-moment ratio diagrams (Hosking, 1990; Peel et al., 2001), which gives a visual indication of how well the probability distributions fits the data.

The L-moment ratios $\tau_{3}$ and $\tau_{4}$ are calculated as follows:

$\tau_{3}=\frac{\lambda_{3}}{\lambda_{2}}$ 
$\tau_{4}=\frac{\lambda_{4}}{\lambda_{2}}$

where $\lambda_{2}, \lambda_{3}$ and $\lambda_{4}$ are the L-moments of the river flow or reservoir storage series, obtained from probability-weighted moments (PWMs) using the formulae:

$\lambda_{1}=w_{0}$

$\lambda_{2}=w_{0}-2 w_{1}$

$\lambda_{3}=w_{0}-6 w_{1}+6 w_{2}$

$\lambda_{4}=w_{0}-12 w_{1}+30 w_{2}-20 w_{3}$

The PWMs of order $s$ were calculated as:

$w_{s}=\frac{1}{N} \sum_{i=1}^{N}\left(1-F_{i}\right)^{s} x_{i}$

where $F_{i}$ is a frequency estimator calculated following the approach of Hosking (1990), where:

$F_{i}=\frac{i-0.35}{N}$

Figure 4 shows the L-moment ratio diagrams for the runoff monthly series. The symbols group the monthly series in seasons (winter, spring, summer and autumn), which enables visual assessment. The diagram shows that the majority of the runoff monthly series had positive skew. However, no clear patterns were evident in relation to the most suitable probability distribution to fit the series, suggesting that it was not possible to select a unique probability distribution based on a visual inspection. Kroll and Vogel (2002) used a quantitative approach to select the most suitable distribution to fit low flow series according to the orthogonal distance between the sample Lmoments at site $i$ and the L-moment relationship for a specific distribution. They indicated that the closer the sample L-moment ratios are to a probability distribution's L-moment ratio relationship the choice of distribution is better for describing the series. We have followed this approach to select the most suitable distribution for each monthly streamflow series, by means of the calculation of the 
orthogonal distance between the sample L-moments at site $i$ and the L-moment relationship for the six distributions described above. We always selected the distribution that showed the minimum orthogonal distance to the sample to obtain the $F(x)$ for each monthly streamflow series. This method is known as the Minimum Orthogonal Distance (MD).

2. The second approach is known as the Best Monthly Fit approach (BMF), which is based on the Kolmogorov-Smirnov (KS) test (Siegel and Castelan, 1988). This test was used to compare a streamflow series with a reference probability distribution. It is based on the difference between the empirical distribution function, $\operatorname{ECDF}(\mathrm{X})$, and the cumulative distribution function, $\operatorname{CDF}(\mathrm{X})$, following a given probability distribution. On the basis of the KS test a $D$ statistic was obtained, which is the maximum vertical difference between the empirical and the cumulative distribution functions:

$D=\max \left(\max _{i}\left|C D F\left(x_{i}\right)-\frac{r-1}{n}, \frac{r}{n}-C D F\left(x_{i}\right)\right|\right)$

where $r$ is the rank of the observation $i$ in ascending order.

If the runoff series comes from a given cumulative distribution function, then $D$ converges to 0 . In other words, smaller values of $D$ imply a better fit of the streamflow series to the probability distribution. Therefore, to obtain the $F(x)$ for each monthly streamflow series we selected the probability distribution that showed the smallest $D$ statistic. The distribution was rejected if $D$ was greater than the critical value $(\alpha=0.05)$.

For the results obtained from each approach we compared the statistical properties of the constructed SSI series in terms of the average, standard deviation, and expected frequencies of the most extreme values.

\section{Results}


Figure 5 shows twelve boxplots of the KS $D$ statistic for the monthly streamflow series of the 98 stations. Based on the critical level $(\alpha=0.05)$ the six analyzed distributions provided an adequate fit to the streamflow series, as the $D$ values were in most cases below the critical value of $D=0.169$. From Figure 5 it is very difficult to determine which probability distribution provides the best fit to the series, as there are marked differences among the various months of the year. Figure 6 shows twelve box-plots with the orthogonal distance between the sample L-moments and the L-moment relationship for each one of the distributions. There are some seasonal contrasts (e.g., higher orthogonal distances in summer than in winter months) but the main pattern is the large differences between the distributions with low distances for each monthly series.

Moreover, Figures 7 and 8 indicates that there was no clear spatial pattern in the probability distributions that showed the best fit and the minimum distance to the monthly streamflow series, respectively. Thus, the probability distribution providing the best fit for gauging stations along the same river course often changed. Moreover, in addition to the large spatial variability there was high seasonal variability, and the most common situation was to find a different probability distribution that shows the best fit to the streamflow series of each month. There was no probability distribution that showed a better overall fit for a particular region or month.

In addition, there are noticeable differences in the selected distributions according to the BMF or MD approaches. Table 2 shows the frequency with which each distribution was selected for each month according to the two different approaches. The numbers represent the percentage of the monthly streamflow series in which the minimum D statistic of the KS test or the MD is obtained for each distribution. For the BMF, the Generalized Pareto distribution showed the best fit for $22 \%$ of the series. The log-normal and log-logistic distributions showed the best fit for $18 \%$ of the series, and the Weibull was best in $17 \%$. The two least suitable were the GEV and the PIII distributions, which showed the best fit in $13 \%$ and $12 \%$ of series, respectively. There were some seasonal differences; for example, the Generalized Pareto distribution showed the best fit in the highest 
percentage of stations in spring (23-30\%), but in late autumn and early winter the log-normal distribution showed the best fit in the highest percentage of stations (28-32\%), and in summer and autumn it was the log-logistic distribution (28-36\%). The other six distributions did not show any seasonal dominance. The pattern is similar for the MD approach, since the Generalized Pareto showed the minimum orthogonal distance for the $23 \%$ of the cases and the seasonal percentages are very close to those obtained using the BMF. However, although the percentages are comparable, in the $52 \%$ of the cases (611 of the 1176 monthly series) the selected distribution was different between the BMF and the MD approaches.

The reasons of why certain distributions fit better than others for different months can be driven by physical or climatic factors. For example, late spring and early summer are characterised by high flows but also by high inter-annual differences given the large climate variability that characterises the region. This could explain that during these months the Generalized Pareto distribution showed the best fit in a high percentage of the cases since this is an extreme value distribution widely used for modelling excesses over high thresholds. On the contrary, during late fall and early winter the precipitation events commonly have a frontal origin; they are not very extreme in terms of their intensity over short periods, and flashy high flows are more rare. This behaviour could explain why log-logistic or log-normal distributions showed the best fit in several stations. In any case, the variability found was very high, and given the high spatial variability showed in Figures 7 and 8 , it is very difficult to identify patterns of dominant distributions to fit the data in some months and areas. Based on the findings of high spatial and seasonal differences in the statistical characteristics of the streamflow series, and large variability in the probability distributions that provided the best fit to the data, it does not seem feasible to select a single probability distribution for the entire dataset, or for specific regions or months. An alternative approach was to seek the most suitable probability distribution for each station and monthly series. Figures 9 and 10 show representative examples of the evolution of the SSI at two stations with very different characteristics: the Ebro River at the 
Sástago station (in the middle course of the main river, with an average annual flow of 7549 $\mathrm{Hm}^{3} /$ year) and the Segre River at the Puigcerdá station (in the headwaters of a mountain river, with an average annual flow of $126 \mathrm{Hm}^{3} /$ year). The figures represent $7 \mathrm{SSI}$ series for each station, corresponding to the six probability distributions and the BMF and MD approaches, and show that irrespective of the probability distribution or BMF/MD approach used, the major dry and moist episodes were clearly identified. At the Sástago station the main droughts were recorded in 1948-1949, 1955 and the decades of 1980, 1990 and 2000. There was some agreement with the drought episodes recorded at the Puigcerdá station, mainly in the decades of 1940 and 2000. Based on visual inspection it was very difficult to distinguish among the series calculated using the various probability distributions or the BMF/MD approaches. Nevertheless, some common features were evident: i) the PIII distribution tended to overestimate the magnitude of the negative anomalies; ii) the Generalized Pareto distribution tended to generate higher values than the other distributions; iii) The Generalized Pareto and the Weibull distributions did not show solution for some low/high streamflow values (as the values of the index tend to $-\infty$ or $+\infty$ given the shape of the probability density functions). In these cases the values had to be truncated to the corresponding probability of 1 in 100 years to have a value in the index. This explains why some contiguous months had the same negative value. The SSI obtained from the log-normal, GEV and log-logistic distributions and the BMF and MD approaches showed similar characteristics in terms of the magnitude of the most extreme values, highlighting the difficulty of selecting the most appropriate distribution by visual inspection alone.

As we could not reject for the majority of the stations the hypothesis that the twelve monthly series came from at least one of the six analyzed distributions (Table 3), we made a statistical comparison based on the expected statistical properties of the SSI. As the SSI is a standardized variate, it is expected that the long-term average of the index will equal 0 , and its standard deviation will equal 1. Figure 11 shows two boxplots of the average and standard deviation of the SSI using the six 
probability distributions and the BMF and MD approaches. The indices based on some distributions were deficient in terms of the expected average and standard deviation. For example, the mean of the average values was negative for the log-normal and the PIII distributions, whereas for the other distributions and the BMF and MD approaches the mean of the average SSI was close to 0. The range of average values among the stations was very high for the log-normal and PIII distributions, which introduced a substantial limitation in the SSI series obtained from these distributions. As some of the series were biased, it was difficult to establish reliable spatial comparisons, as a value of 0 would not represent normal conditions in all cases. The GEV and log-logistic distributions and the BMF approach provided SSI series with averages closest to 0 , and low variability among the stations. The standard deviations of the SSI series also showed marked differences among the eight approaches. Thus, the log-normal and the PIII distributions generated average values much greater than 1, which suggests against their use for the SSI calculation. The other distributions generated values around 1, and the standard deviation for the BMF and MD approaches was closest to 1 .

The comparisons among the indices included the expected frequency of the most extreme SSI values as well as the average and standard deviations. Based on a normal standard distribution, it is expected to find one value lower than -1.65 or higher than 1.65 every 20 years, as these values represent $5 \%$ of the cumulative distribution function. Similarly, an SSI event exceeding \pm 2.33 corresponds to a return period of 100 years. Given the length of the series ( 61 years $\times 12$ months $)$ an average of 36.6 SSI events above (below) $1.65(-1.65)$, or 7.3 events above (below) $2.33(-2.33)$ would be expected. We compared the observed and expected frequency of the values above and below these thresholds, and summarized the results in a boxplot (Figure 12). The observed frequency of positive extreme values tended to follow the expected frequency independent of the approach used for the calculation. Nevertheless, the GEV and log-logistic distributions tended to show a higher frequency of values above 1.65 and a lower frequency of values above 2.33 than did the other distributions. They also showed the highest variability in the observed frequencies among the 
stations. Nevertheless, the most important differences were found for the low values. The GEV and log-logistic distributions tended to underestimate the expected frequency of values below -1.65 . Moreover, the log-normal distribution showed high variability among the stations, in some cases yielding very high frequencies of low SSI values. The BMF and MD approaches showed the closest frequency to the expected values, and also the lowest variability among the 98 stations. The same pattern was observed for the frequency of values less than -2.33 , in which the BMF provided the best result.

Table 4 summarizes, the main limitations in the calculation of the SSI based on each of the six probability distributions and the BMF and the MD approaches. If a unique distribution of probability is selected to fit the twelve monthly streamflow series of a gauging station, the most suitable and flexible probability distributions were the GEV and the log-logistic. The Generalized Pareto and Weibull distributions showed no solution for some negative values, which is a critical limitation for calculation of the index, but they also showed very large differences among stations in the average values of the SSI, and underestimated the expected frequency of extreme negative SSI values. The PIII and log-normal distributions also showed large limitations, mainly in relation to the expected average and standard deviations of the SSI series, which made spatial comparisons of the SSI values difficult. In addition, the PIII distribution also showed an excessive frequency of extreme negative values. The results indicate that rather than using a unique probability distribution for calculation of the SSI over a range of streams with different flow magnitudes and regimes, it is better to select the most suitable distribution for each monthly series according to the BMF of MD approaches based on the probability distribution that shows the best fit to each of the twelve streamflow series at each station for the BMF or the MD approaches. Application of the BMF or MD approaches enabled the limitations of the two most suitable distributions (GEV and log-logistic) to be overcome, as no underestimation of the most negative SSI values, or overestimation of the extreme positive SSI values, was observed. 


\section{Discussion and conclusions}

A key recommendation of this study is to assess and if necessary use different probability distributions for each gauging station and month of the year for calculating a SSI. We compared the performance of this calculation procedure by means of two different approaches (the BMF and the MD) with the use of a single probability distribution for an entire region over the twelve months of a year. The analysis was conducted in the Ebro River basin, an area that exhibits large variability among river regimes, the frequency characteristics of streamflows, and flow magnitudes. The BMF and the MD approaches showed the greatest flexibility in accounting for the variety of conditions found within the basin, and enabled the problems associated with the use of a single distribution to be overcome. Thus, both approaches provide a robust index that guarantees the spatial and temporal comparability of drought conditions. They provide very similar results in terms of the expected average, variance and the occurrence of extremes in the series of the drought indices.

The procedure for obtaining the SSI was based on the conversion of the streamflow magnitudes to standardized anomalies ( $z$-scores). For this purpose we fitted various probability distributions to the available streamflow data. Selection of the most suitable probability distribution to fit the empirical streamflow data is usually based on a visual inspection of L-moment diagrams (Hosking, 1990), or a goodness-of-fit test. We found that neither of these approaches provided a sufficient basis for choosing a single probability distribution for the dataset, even if the analyses were made by regions, streams or months. The visual inspection of the L-moment diagrams showed that none of the six probability distributions was best able to fit the streamflow series. Moreover, a goodness-of-fit test did not help in the identification of a unique probability distribution, as in the majority of cases the null hypothesis (that the series follows at least one of the six distributions) could not be rejected. Therefore, neither approach help select a single probability distribution for computing the SSI. 
Nevertheless, when the SSI series obtained were compared, they showed marked differences in their statistical properties (mean and standard deviation), and in the estimation of extreme quantiles.

Previous attempts to calculate a SSI have been based on a unique probability distribution (Zaidman et al., 2001; López-Moreno et al., 2008; Mo, 2008; Nabaltis and Tsakiris, 2009; Lorenzo-Lacruz et al., 2010). Nevertheless, Shukla and Wood (2008) warned of the need to use different probability distributions to fit the streamflow series when calculating a SSI. Our results also provide evidence that the use of a unique probability distribution for each gauging station does not enable a reliable index to be obtained because of the large variability in the statistical properties of the monthly series. If a unique probability distribution is to be used to obtain the SSI, our results suggest that the GEV or the log-logistic distribution be selected, although both tended to underestimate the frequency of the most extreme negative values in our dataset. None of the other four distributions we tested are recommended for use in a single distribution approach to obtaining a SSI, as the derived indices were unsatisfactory. For example, the Generalized Pareto and Weibull distributions were not defined for some values, and the PIII and log-normal distributions did not generate reliable average and standard deviation values because they commonly diverged from 0 and 1 , respectively. Moreover, large differences can occur among stations, making spatial comparability of the series very difficult. Thus, while some previous studies have recommended the use of the log-normal distribution to fit monthly streamflow data (Kroll and Vogel, 2002; Yue and Wang, 2004; Chen et al., 2006; McMahon et al., 2007) and to obtain standardized streamflows (Zaidman et al., 2001; Nabaltis and Tsakiris, 2009), we demonstrated that the use of this distribution is inappropriate in a region with high variability in the river regimes and streamflow characteristics. The PIII has also been widely used for flow frequency analyses (Bobee and Rasmussen, 1995; Saf, 2009). The results of the KS test for the streamflow series in our study indicate that in most cases ( $>95 \%$ for each monthly series) the PIII distribution fitted the streamflow series well. Nevertheless, the SSI values obtained using this distribution showed similar problems to those found for the log-normal distribution (average SSI 
non equal to 0 , High variance in the SSI averages, standard deviation $<>1$ ), and there was also an excessive frequency of negative values found. Many of these limitations could be avoided by using a combined approach like the BMF or the MD. We found large spatial variability and seasonal differences in the probability distributions that showed the best fit to the streamflow series. Thus, the maps obtained did not show any spatial pattern suggesting that a particular probability distribution fitted the data better for a region or a specific season. One of the main properties of a drought index is that it must enable spatial comparability, and most research into climate drought indicators has aimed to develop procedures that ensure that the drought conditions quantified by a drought index are comparable among different regions (Wells et al., 2004; Vicente-Serrano et al., 2010). The BMF or the MD approaches allow development of a reliable standardized index, with the expected averages, standard deviations and frequencies of extreme positive and negative values to be obtained. Thus, the SSI obtained using any of both approaches at a particular gauging station can be compared to the SSI obtained at another station. Moreover, in addition to the values of the index being spatially comparable, they are also temporally independent of the streamflow regimes.

Using the SSI it is also possible to characterize the magnitude and duration of droughts, and to apply the widely used low-flow frequency analysis based on the run theory (Yevjevich, 1967; Smakhtin, 2001). However, some advantages accrue with respect to other procedures, as the magnitude of the droughts identified can be compared spatially, and the truncation levels can be defined according to the theoretical return periods. Moreover, as the SSI is measured in the same units that are currently used for other climate drought indices, comparisons between hydrological and climate droughts are possible, thus aiding study of the complex interactions between the two phenomena.

One of the main objectives of drought indices is their use for drought monitoring, early warning and to improve drought preparedness and mitigation (Svoboda et al., 2002 and 2004). Current drought monitoring systems are largely based on climate drought indices, with the inclusion of additional hydrological drought indices, such as the SSI, could improve the performance of these systems. The 
capacity of a SSI to add reliable and direct information about the spatial extent and severity of hydrological drought conditions will provide a convenient way to quantify the level of risk in a way that is accurate and easily understand by end-users.

\section{Acknowledgements}

This work has been supported by the research projects CGL2008-01189/BTE and CGL200611619/HID financed by the Spanish Commission of Science and Technology and FEDER, EUROGEOSS (FP7-ENV-2008-1-226487) and ACQWA (FP7-ENV-2007-1- 212250) financed by the VII Framework Programme of the European Commission, "Las sequías climáticas en la cuenca del Ebro y su respuesta hidrológica" and "La nieve en el Pirineo aragonés: Distribución espacial y su respuesta a las condiciones climáticas" Financed by "Obra Social La Caixa" and the Aragón Government.

\section{References}

Abramowitz, M. and Stegun, I.A., (1965): Handbook of Mathematical Functions. Dover Publications, New York.

Beersma, J.J. and Buishand, T.A., (2004): Joint probability of precipitation and discharge deficits in the Netherlands. Water Resources Research, 40: DOI: 10.1029/2004WR003265.

Beguería, S., Vicente-Serrano, S.M., López-Moreno, J.I. and García-Ruiz, J.M., (2009): Annual and seasonal mapping of peak intensity, magnitude and duration of extreme precipitation events across a climatic gradient, North-east Iberian Peninsula. International Journal of Climatology 29: $1759-1779$.

Bobee, B., Mathier, L., Perron H, et al., (1996): Presentation and review of some methods for regional flood frequency analysis. Journal of Hydrology 186: 63-84.

Bobée, B. and Ashkar, F., (1991): The Gamma Family and Derived Distributions Applied in Hydrology. Water Resources Publications, Littleton, CO.

Bobee, B. and Rasmussen, P.F. (1995): Recent advances in flood frequency-analysis. Reviews of Geophysics 33: 1111-1116.

Burn, D.H., (1997): Catchment similarity for regional flood frequency analysis using seasonality measures. Journal of Hydrology 202:212-230.

Chen, Y.D., Huang, G., Shao, Q.X., et al., (2006): Regional analysis of low flow using L-moments for Dongjiang basin, South China. Hydrological Science Journal 51: 1051-1064.

Chow, V.T., Maidment, D.R., and Myas, L.W., (1988): Applied Hydrology. MacGraw-Hill. New York.

Clausen, B. and Pearson, C.P., (1995): Regional frequency analysis of annual maximum streamflow drought. Journal of Hydrology 173: 111-130. 
Cuadrat, J.M., Saz, M.A. and Vicente-Serrano, S.M. (2007), Atlas Climático de Aragón. Gobierno de Aragón. 229 pp.

Dracup, J.A., Lee, K. y Paulson, E.G., (1980): On the definition of droughts. Water Resources Research. 16: 297-302.

Edossa, D.Ch., babel, M.S. and Gupta, A.D., (2010): Drought analysis in the wash river basin, Ethiopia. Water Resources Management, 24: 1441-1460.

Fink, A.H., Brücher, T., Krüger, A., Leckebush, G.C., Pinto, J.G. and Ulbrich, U., (2004): The 2003 European summer heatwaves and drought-synoptic diagnosis and impacts. Weather 59: 209-216.

Fleig, A.K., Tallaksen, L.M., Hisdal, H. y Demuth, S. (2006): A global evaluation of streamflow drought characteristics. Hydrology and Earth Systems Science, 10: 532-552.

Guttman, N.B., (1999): Accepting the standardized precipitation index: a calculation algorithm. Journal of the American Water Resources Association. 35: 311-322.

Hannaford, J., Lloyd-Hughes, B., Keef, C. Parry, S. and Prudhomme, C., (2010): Examining the large-scale spatial coherence of European drought using regional indicators of precipitation and streamflow deficit. Hydrological Processes, DOI: 10.1002/hyp. 7725.

Havens, A.V., (1954): Drought and agriculture. Weatherwise, 7: 51-55.

Heim, R.R., (2002): A review of twentieth-century drought indices used in the United States. Bulletin of the American Meteorological Society. 83: 1149-1165.

Hirsch, R.M., (1982): A comparison of four streamflow record extension techniques: Water Resources Research,18: 1081-1088.

Hisdal, H. and Tallaksen, L.M., (2003): Estimation of regional meteorological and hydrological drought characteristics. Journal of Hydrology 281: 230-247.

Hosking, J.R.M., Wallis, J.R. and Wood, E.F., (1985): Estimation of the generalized extreme-value distribution by the method of probability-weighted moments. Technometrics, 27: 251-261.

Hosking, J.R.M., (1986): The theory of probability weighted moments. Research Report RC12210. IBM Research Division, Yorktown Heights, NY.

Hosking, J.R.M., (1990): L-Moments: Analysis and estimation of distributions using linear combinations of order statistics. Journal of Royal Statistical Society B, 52: 105-124.

Hosking, J.R.M. and Wallis, J.R., (1993): Some statistics useful in regional frequency analysis. Water Resources Research 29: 271-281.

Kroll, C.N., and Vogel, R.M., (2002): Probability distribution of low streamflow series in the United States. Journal of Hydrologic Engineering 7: 137-146.

López-Moreno, J.I., Vicente-Serrano, S.M., Beguería, S. García-Ruiz, J.M., Portela, M. M., Almeida, A. B. (2009): Downstream propagation of hydrological droughts in highly regulated transboundary rivers: the case of the Tagus River between Spain and Portugal. Water Resources Research 45, W02405, doi:10.1029/2008WR007198.

Lorenzo-Lacruz, J., Vicente-Serrano, S.M., López-Moreno, J.I., Beguería, S., García-Ruiz, J.M., Cuadrat, J.M. (2010) The impact of droughts and water management on various hydrological systems in the headwaters of the Tagus River (central Spain). Journal of Hydrology, 386: 1326.

McKee, T.B.N., J. Doesken, and J. Kleist, 1993: The relationship of drought frecuency and duration to time scales. Eight Conf. On Applied Climatology. Anaheim, CA, Amer. Meteor. Soc. 179184.

McMahon, T.A., Pegram, G.G.S., Vogel, R.M., et al. (2007): Revisiting reservoir storage-yield relationships using a global streamflow database. Advances in Water Resources 30: 18581872.

Meehl, G.A., Karl, T., Easterling, D.R., Changnon, S., et al., (2000): An introduction to trends in extreme weather and climate events: observations, socioeconomic impacts, terrestrial 
ecological impacts, and model projections. Bulletin of the American Meteorological Society. 81: 413-416.

Mishra, A.K. and Singh, V.P., (2010): A review of drought concepts Review Article. Journal of Hydrology 391: 202-216.

Mo, K.C., (2008): Model-Based Drought Indices over the United States. Journal of Hydrometeorology, 9: 1212-2130.

Modarres, R. and Sarhadi, A., (2010): Frequency Distribution of Extreme Hydrologic Drought of Southeastern Semiarid Region, Iran. Journal of Hydrologic Engineering 15: 255-264.

Mudelsee, M. (2007): Long memory of rivers from spatial aggregation, Water Resources Research, vol. 43.

Nabaltis, I. and Tsakiris, G., (2009): Assessment of hydrological drought revisited. Water Resources Management, 23: 881-897.

Nicholson, S.E., (2001): Climatic and environmental change in Africa during the last two centuries. Climate Research 17: 123-144.

Obasi, G.O.P., (1994): WMO`s role in the international decade for natural disaster reduction. Bulletin of the American Meteorological Society. 75: 1655-1661.

Rao, A.R. and Hamed, K.H., (2000): Flood frequency analysis. CRC Press. 350 pp.

Redmond, K.T., (2002): The depiction of drought. Bulletin of the American Meteorological Society. 83: 1143-1147.

Riggs, H.C., (1973): Regional analyses of streamflow characteristics. Tech. Rep., US Geol. Surv. Techniques of Water-Resources Investigations, book 4, Chap. B3, 15pp.

Saf, B. (2009): Regional Flood Frequency Analysis Using L-Moments for the West Mediterranean Region of Turkey. Water Resources Management 23: 531-551.

Shi, P., Chen, X., Qu, S.M., et al., (2010): Regional Frequency Analysis of Low Flow Based on L Moments: Case Study in Karst Area, Southwest China. Journal of Hydrologic Engineering, 15: 370-377.

Siegel, S., and Castelan N. J., (1988): Nonparametric Statistics for the Behavioral Sciences, McGraw-Hill, New York.

Singh, V.P. and Guo, F.X.Y., (1993): Parameter estimation for 3-parameter log-logistic distribution (LLD3) by Pome. Stochastic Hydrology and Hydraulics, 7: 163-177.

Shukla, S. and Wood, A., (2008): Use of a standardized runoff index for characterizing hydrologic drought. Geophysical Research Letters, 35: doi: 10.1029/2007GL032487.

Smakhtin, V.U., (2001): Low flow hydrology: a review. Journal of Hydrology, 240: 147-186.

Stahl, K., (2001): Hydrological drought—a study across Europe. Albert-Ludwigs Universität Freiburg: Geowissenschaftlichen Fakultät. Freiburg.

Svoboda, M. et al., (2002): The drought monitor. Bulletin of the American Meteorological Society, 83: 1181-1190.

Svoboda, M.D., Hayes, M.J., Wilhite, D.A. and Tadesse, T., (2004): Recent advances in drought monitoring. Bulletin of the American Meteorological Society, 5237-5240.

Tallaksen, L.M., Madsen, H. and Clausen, B., (1997): On the definition and modeling of streamflow drought duration and deficit volume. Hydrological Sciences Journal 42: 15-33.

Tallaksen, L.M. and van Lanen, H.A.J., (2004): Hydrological Drought_-Processes and Estimation Methods for Streamflow and Groundwater. Elsevier: Amsterdam.

Tallaksen, L.M., Hisdal, H. and Van Lanen, H.A.J., (2009): Space-time modelling of catchment scale drought characteristics. Journal of Hydrology 375: 363-372.

UN, (2008): Trends in sustainable development. Agriculture, rural development, land, desertification and drought. Department of Economic and Social Affairs. United Nations. New York.

Vasiliades, L. and Loukas, A., (2009): Hydrological response to meteorological drought using the Palmer drought indices in Thessaly, Greece. Desalination 237: 3-21. 
Vicente-Serrano, S.M. and López-Moreno, J.I., (2005), Hydrological response to different time scales of climatological drought: an evaluation of the standardized precipitation index in a mountainous Mediterranean basin. Hydrology and Earth System Sciences 9: 523-533.

Vicente-Serrano, S.M., (2006), Differences in spatial patterns of drought on different time scales: an analysis of the Iberian Peninsula. Water Resources Management 20: 37-60.

Vicente-Serrano, S.M., Lanjeri, S. and López-Moreno, J.I. (2007), Comparison of different procedures to map reference evapotranspiration using geographical information systems and regression-based techniques. International Journal of Climatology, 27: 1103-118.

Vicente-Serrano S.M., Beguería, S. and López-Moreno, J.I., (2010): A Multi-scalar drought index sensitive to global warming: The Standardized Precipitation Evapotranspiration Index SPEI. Journal of Climate 23: 1696-1718.

Vicente-Serrano, S.M., Beguería, S., López-Moreno, J.I., Angulo, M., El Kenawy, A. (2010b): A new global $0.5^{\circ}$ gridded dataset (1901-2006) of a multiscalar drought index: comparison with current drought index datasets based on the Palmer Drought Severity Index. Journal of Hydrometeorology. 11: 1033-1043.

Vidal, J.P., Martin, E., Franchist'eguy, L., Habets, F., Soubeyroux, J.M., Blanchard, M. and Baillon, M., (2010): Multilevel and multiscale drought reanalysis over France with the Safran-IsbaModcou hydrometeorological suite. Hydrology and Earth System Science 14: 459-478.

Vogel, R.M., and Stedinger, J.R., (1985): Minimum variance streamflow record augmentation procedures: Water Resources Research, 21: 715-723.

Vogel, R.M., Thomas Jr. W.O., and McMahon, T.A., (1993): Flood frequency model selection in Southwestern United States. Journal Water Research Planning and Management ASCE: 353366.

Wilhite, D.A., (1993): Drought assessment, management and planning: Theory and case studies. Kluwer. Boston.

Wells, N., Goddard, S. and Hayes, M.J., (2004): A self-calibrating Palmer drought severity index. Journal of Climate, 17: 2335-2351.

Yevjevich, V.M., (1967): An objective approach to definition and investigation of continental hydrologic droughts. Hydrologic paper 23. Universidad de Colorado.

Yue, S. and Wang, C.Y., (2004): Possible regional probability distribution type of Canadian annual streamflow by L-moments. Water Resources Management 18: 425-438.

Yue, S. and Pilon, P., (2005): Probability distribution type of Canadian annual minimum streamflow. Hydrological Science Journal 50: 427-438.

Yue, S. and Hashino, M., (2007): Probability Distribution of Annual, Seasonal and Monthly Precipitation in Japan. Hydrological Sciences Journal, 52: 863-877.

Zaidman, M.D., Rees, H.G., and Young, A.R., (2001): Spatio-temporal development of streamflow droughts in north-west Europe. Hydrology and Earth System Sciences 5: 733-751.

Zelenhasic, E. and Salvai, A., (1987): A method of streamflow drought analysis. Water Resources Research 23: 156-168. 


\section{Figure legends}

Figure 1. Location of the study area and spatial distribution of the gauging stations used in the study. Figure 2. Frequency histograms of the (i) January, (ii) March and (iii) May runoff series at the Sástago station (Ebro River). The theoretical curves of the log-logistic, Weibull and Pearson type III distributions are also shown.

Figure 3. Frequency histogram of the May runoff series at the Sástago station (Ebro River), and the curves of the six theoretical distributions.

Figure 4. L-moment ratio diagrams. The different symbols represent the statistics of various seasonal series. Black triangles: winter; white triangles: autumn; white circles: summer; black squares: spring. Figure 5. Boxplot of the KS $D$ statistic obtained for the six probability distributions from the monthly series of the 98 stations.

Figure 6. Boxplot of the orthogonal distance between the sample L-moments at site $\mathrm{i}$ and the Lmoment relationship for a specific distribution obtained for the six probability distributions from the monthly series of the 98 stations.

Figure 7. Spatial pattern of the probability distribution showing the best fit to each monthly runoff series.

Figure 8. Spatial pattern of the probability distribution showing the minimum orthogonal distance to each monthly runoff series.

Figure 9. Evolution of the SSI obtained using the six selected probability distributions and the BMF approach for the Sástago station in the Ebro River.

Figure 10. Evolution of the SSI obtained using the six selected probability distributions and the BMF approach for the Puigcerdá station in the Segre River.

Figure 11. Boxplot of the average and standard deviation values of the SSI at the 98 gauging stations. The plots show the lower quartile, median and upper quartile, and the mean (dashed). Whiskers represents the 90th (top) and 10th (bottom) percentiles: GEV: General Extreme Value; 
LN: log-normal; PIII: Pearson type III; G-PAR: Generalized Pareto; L-LOG: log-logistic; WEI: Weibull.

Figure 12. Boxplot of the frequency of low $(<-1.65$ and $<-2.33)$ and high values $(>1.65$ and $>$ 2.33) of the SSI at the 98 gauging stations The plots show the lower quartile, median and upper quartile, and the mean (dashed). Whiskers represents the 90th (top) and 10th (bottom) percentiles: GEV: General Extreme Value; LN: log-normal; PIII: Pearson type III; G-PAR: Generalized Pareto; L-LOG: log-logistic; WEI: Weibull. 


\section{Table captions}

Table 1. Cumulative distribution functions of the Generalized Pareto, log-logistic, log-normal, Pearson type III, General Extreme Value and Weibull distributions, and the equations used to obtain the distribution parameters according to the L-moment procedure.

Table 2. Percentage of the monthly series in which each probability distribution shows the best fit and the minimum orthogonal distance.

Table 3. Percentage of cases in which the hypothesis that the monthly runoff series come from the corresponding probability distribution is rejected.

Table 4. Main limitations in calculation of the SSI based on various probability distributions. Gray cells show that a particular distribution does not have this limitation. 


\begin{tabular}{|c|c|c|c|}
\hline & $\mathrm{F}(\mathrm{x})$ & Parameter estimation & References \\
\hline $\begin{array}{l}\text { Generalized } \\
\text { Pareto }\end{array}$ & $F(x)=1-\left[1-\frac{\kappa}{\alpha}(x-\varepsilon)\right]^{1 / \kappa}$ & $\begin{array}{l}\kappa=\frac{\left(1-3 \tau_{3}\right)}{\left(1+\tau_{3}\right)} \\
\alpha=\lambda_{2}(1+\kappa)(2+\kappa) \\
\varepsilon=\lambda_{1}-\lambda_{2}(2+\kappa)\end{array}$ & $\begin{array}{l}\text { Hosking } \\
\text { (1990) }\end{array}$ \\
\hline Log-logistic & $F(x)=\left[1+\left(\frac{\alpha}{x-\gamma}\right)^{\beta}\right]^{-1}$ & $\begin{aligned} \beta & =\frac{2 w_{1}-w_{0}}{6 w_{1}-w_{0}-6 w_{2}} \\
\alpha & =\frac{\left(w_{0}-2 w_{1}\right) \beta}{\Gamma(1+1 / \beta) \Gamma(1-1 / \beta)} \\
\gamma & =w_{0}-\alpha \Gamma(1+1 / \beta) \Gamma(1-1 / \beta)\end{aligned}$ & $\begin{array}{l}\text { Singh et al. } \\
(1993)\end{array}$ \\
\hline Lognormal & $\begin{array}{l}F(x)=\Phi\left(\frac{\ln (x-a)-\mu}{\sigma}\right) \\
\text { where } \Phi \text { is the standard } \\
\text { normal cumulative distribution } \\
\text { function }\end{array}$ & $\begin{array}{l}\sigma=0.999281 z-0.006118 z^{2}+0.000127 z^{5} \\
z=\sqrt{\frac{8}{3}} \Phi^{-1}\left(\frac{1+\tau_{3}}{2}\right) \\
\mu=\ln \left[\frac{\lambda_{2}}{\operatorname{erf}\left(\frac{\sigma}{2}\right)}\right]-\frac{\sigma^{2}}{2} \\
\operatorname{erf} \text { is the Gauss error function: } \\
\operatorname{erf}\left(\frac{\sigma}{2}\right)=2 \Phi\left(\frac{\sigma}{2} \sqrt{2}\right)-1 \\
a=\lambda_{1}-e^{\mu+\frac{\sigma^{2}}{2}}\end{array}$ & $\begin{array}{l}\text { Hosking } \\
(1990)\end{array}$ \\
\hline Pearson III & $F(x)=\frac{1}{\alpha \Gamma(\beta)} \int_{\gamma}^{x}\left(\frac{x-\gamma}{\alpha}\right)^{\beta-1} e^{-\left(\frac{x-\gamma}{\alpha}\right)}$ & $\begin{array}{l}\text { If } \tau_{3} \geq 1 / 3, \text { then } \tau_{\mathrm{m}}=1-\tau_{3}: \\
\beta=\frac{\left(0.36067 \tau_{m}-0.5967 \tau^{2}+0.25361 \tau^{3}\right)}{\left(1-2.78861 \tau_{m}+2.56096 \tau^{2}{ }_{m}-0.77045 \tau^{3}{ }_{m}\right)} \\
\text { If } \tau_{3}<1 / 3, \text { then } \tau_{\mathrm{m}}=3 \pi \tau_{3}^{2}: \\
\beta=\frac{\left(1+0.2906 \tau_{m}\right)}{\left(\tau_{m}+0.1882 \tau_{m}^{2}+0.0442 \tau_{m}^{3}\right)} \\
\alpha=\sqrt{\pi} \lambda_{2} \frac{\Gamma(\beta)}{\Gamma(\beta+1 / 2)} \\
\gamma=\lambda_{1}-\alpha \beta\end{array}$ & $\begin{array}{l}\text { Hosking } \\
(1990)\end{array}$ \\
\hline GEV & $F(x)=e^{-\left[1-\kappa\left(\frac{x-\mu}{\alpha}\right)\right]^{\frac{1}{\kappa}}}$ & $\begin{array}{l}\kappa=7.859 C+2.9554 C^{2} \\
C=\frac{2}{3+\tau_{3}}-0.6309\end{array}$ & $\begin{array}{l}\text { Hosking et al. } \\
\text { (1985) }\end{array}$ \\
\hline
\end{tabular}




\begin{tabular}{|l|l|l|l|}
\hline & $\begin{array}{l}\alpha=\frac{\lambda_{2} \kappa}{\Gamma(1+\kappa)\left(1-2^{-\kappa}\right)} \\
\mu=\lambda_{1}+\frac{\alpha}{\kappa}[\Gamma(1+\kappa)-1]\end{array}$ & Hosking (1986) \\
\hline Weibull $F(x)=1-e^{-\left(\frac{x-m}{a}\right)^{b}}$ & $\begin{array}{l}\left(7.859 C+2.9554 C^{2}\right) \\
C=\frac{2}{3-\tau_{3}}-0.6309 \\
a=\frac{\lambda_{2}}{\Gamma\left(1+\frac{1}{b}\right)\left(1-2^{-\frac{1}{b}}\right)} \\
m=\lambda_{1}-a \Gamma\left(1+\frac{1}{b}\right)\end{array}$ & \\
\hline
\end{tabular}

Table 1. 


\section{Best Monthly Fit}

\begin{tabular}{|c|c|c|c|c|c|c|c|c|c|c|c|c|c|}
\hline Distribution & January & February & March & April & May & June & July & August & September & October & November & December & Annual \\
\hline GEV & $7 \%$ & $16 \%$ & $6 \%$ & $12 \%$ & $6 \%$ & $15 \%$ & $13 \%$ & $14 \%$ & $17 \%$ & $13 \%$ & $17 \%$ & $21 \%$ & $13 \%$ \\
\hline PEARSON III & $13 \%$ & $15 \%$ & $15 \%$ & $9 \%$ & $18 \%$ & $5 \%$ & $7 \%$ & $12 \%$ & $11 \%$ & $10 \%$ & $11 \%$ & $11 \%$ & $12 \%$ \\
\hline GEN. PARETO & $27 \%$ & $17 \%$ & $23 \%$ & $23 \%$ & $30 \%$ & $35 \%$ & $20 \%$ & $14 \%$ & $14 \%$ & $14 \%$ & $23 \%$ & $17 \%$ & $22 \%$ \\
\hline LOGNORMAL & $21 \%$ & $19 \%$ & $17 \%$ & $11 \%$ & $15 \%$ & $13 \%$ & $12 \%$ & $9 \%$ & $15 \%$ & $23 \%$ & $32 \%$ & $28 \%$ & $18 \%$ \\
\hline LOGLOGISTIC & $12 \%$ & $16 \%$ & $16 \%$ & $13 \%$ & $13 \%$ & $17 \%$ & $20 \%$ & $36 \%$ & $28 \%$ & $29 \%$ & $7 \%$ & $9 \%$ & $18 \%$ \\
\hline WEIBULL & $19 \%$ & $15 \%$ & $21 \%$ & $31 \%$ & $16 \%$ & $14 \%$ & $27 \%$ & $14 \%$ & $14 \%$ & $10 \%$ & $9 \%$ & $13 \%$ & $17 \%$ \\
\hline \multicolumn{14}{|c|}{ Minimum Distance } \\
\hline GEV & $10 \%$ & $12 \%$ & $7 \%$ & $13 \%$ & $12 \%$ & $9 \%$ & $10 \%$ & $17 \%$ & $16 \%$ & $19 \%$ & $9 \%$ & $18 \%$ & $13 \%$ \\
\hline PEARSON III & $19 \%$ & $14 \%$ & $14 \%$ & $19 \%$ & $24 \%$ & $21 \%$ & $12 \%$ & $16 \%$ & $11 \%$ & $8 \%$ & $14 \%$ & $13 \%$ & $16 \%$ \\
\hline GEN. PARETO & $25 \%$ & $24 \%$ & $28 \%$ & $26 \%$ & $25 \%$ & $21 \%$ & $22 \%$ & $13 \%$ & $19 \%$ & $14 \%$ & $32 \%$ & $25 \%$ & $23 \%$ \\
\hline LOGNORMAL & $14 \%$ & $30 \%$ & $18 \%$ & $14 \%$ & $13 \%$ & $15 \%$ & $17 \%$ & $9 \%$ & $13 \%$ & $24 \%$ & $22 \%$ & $27 \%$ & $18 \%$ \\
\hline LOGLOGISTIC & $5 \%$ & $9 \%$ & $9 \%$ & $7 \%$ & $10 \%$ & $18 \%$ & $18 \%$ & $35 \%$ & $30 \%$ & $21 \%$ & $8 \%$ & $7 \%$ & $15 \%$ \\
\hline WEIBULL & $27 \%$ & $11 \%$ & $23 \%$ & $20 \%$ & $16 \%$ & $14 \%$ & $19 \%$ & $9 \%$ & $10 \%$ & $13 \%$ & $14 \%$ & $10 \%$ & $16 \%$ \\
\hline
\end{tabular}

Table 2. 
Distribution January February March April May June July August September October November December Annual $\begin{array}{llllllllllllll}\text { GEV } & 3.1 & 4.1 & 1.0 & 2.0 & 1.0 & 2.0 & 3.1 & 2.0 & 3.1 & 5.1 & 3.1 & 4.1 & 2.8\end{array}$

$\begin{array}{llllllllllllll}\text { PEARSON III } & 3.1 & 5.1 & 3.1 & 2.0 & 1.0 & 2.0 & 4.1 & 2.0 & 3.1 & 5.1 & 3.1 & 4.1 & 3.1\end{array}$

GEN.

$\begin{array}{lccccccccccccc}\text { PARETO } & 2.0 & 2.0 & 1.0 & 1.0 & 5.1 & 2.0 & 7.1 & 11.2 & 5.1 & 1.0 & 2.0 & 4.1 & 3.7 \\ \text { LOGNORMAL } & 2.0 & 3.1 & 1.0 & 2.0 & 1.0 & 0.0 & 4.1 & 6.1 & 2.0 & 1.0 & 3.1 & 3.1 & 2.4 \\ \text { LOGLOGISTIC } & 6.1 & 4.1 & 3.1 & 3.1 & 2.0 & 2.0 & 3.1 & 10.2 & 6.1 & 3.1 & 9.2 & 5.1 & 4.8 \\ \text { WEIBULL } & 5.1 & 3.1 & 2.0 & 2.0 & 2.0 & 1.0 & 3.1 & 5.1 & 3.1 & 3.1 & 7.1 & 4.1 & 3.4\end{array}$

Table 3 . 


\begin{tabular}{|c|c|c|c|c|c|c|c|c|}
\hline LIMITATION & BEST FIT & MIN. DIST. & GEV & $\mathrm{LN}$ & PIII & G-PAR & L-LOG & WEI \\
\hline $\begin{array}{l}\text { High frequency } \\
\text { of negative } \\
\text { values }\end{array}$ & & & & & $\checkmark$ & & & \\
\hline $\begin{array}{l}\text { No solution for } \\
\text { some negative } \\
\text { values }\end{array}$ & & & & & & $\checkmark$ & & $\checkmark$ \\
\hline $\begin{array}{l}\text { Average SSI } \prec \\
0\end{array}$ & & & & $\checkmark$ & $\checkmark$ & & & \\
\hline $\begin{array}{l}\text { High variance in } \\
\text { SRI averages }\end{array}$ & & & & $\checkmark$ & $\checkmark$ & $\checkmark$ & & $\checkmark$ \\
\hline $\begin{array}{l}\text { Standard } \\
\text { deviation SSI } \\
\diamond 1\end{array}$ & & & & $\checkmark$ & $\checkmark$ & & & \\
\hline $\begin{array}{l}\text { Underestimation } \\
\text { of expected } \\
\text { negative } \\
\text { extreme SSI }\end{array}$ & & & $\checkmark$ & & & $\checkmark$ & $\checkmark$ & $\checkmark$ \\
\hline $\begin{array}{l}\text { Overestimation } \\
\text { of expected } \\
\text { negative } \\
\text { extreme SSI }\end{array}$ & & & & $\checkmark$ & $\checkmark$ & & & \\
\hline $\begin{array}{l}\text { Overestimation } \\
\text { of expected } \\
\text { positive extreme } \\
\text { SSI }\end{array}$ & & & $\checkmark$ & & & & $\checkmark$ & \\
\hline
\end{tabular}

Table 4 


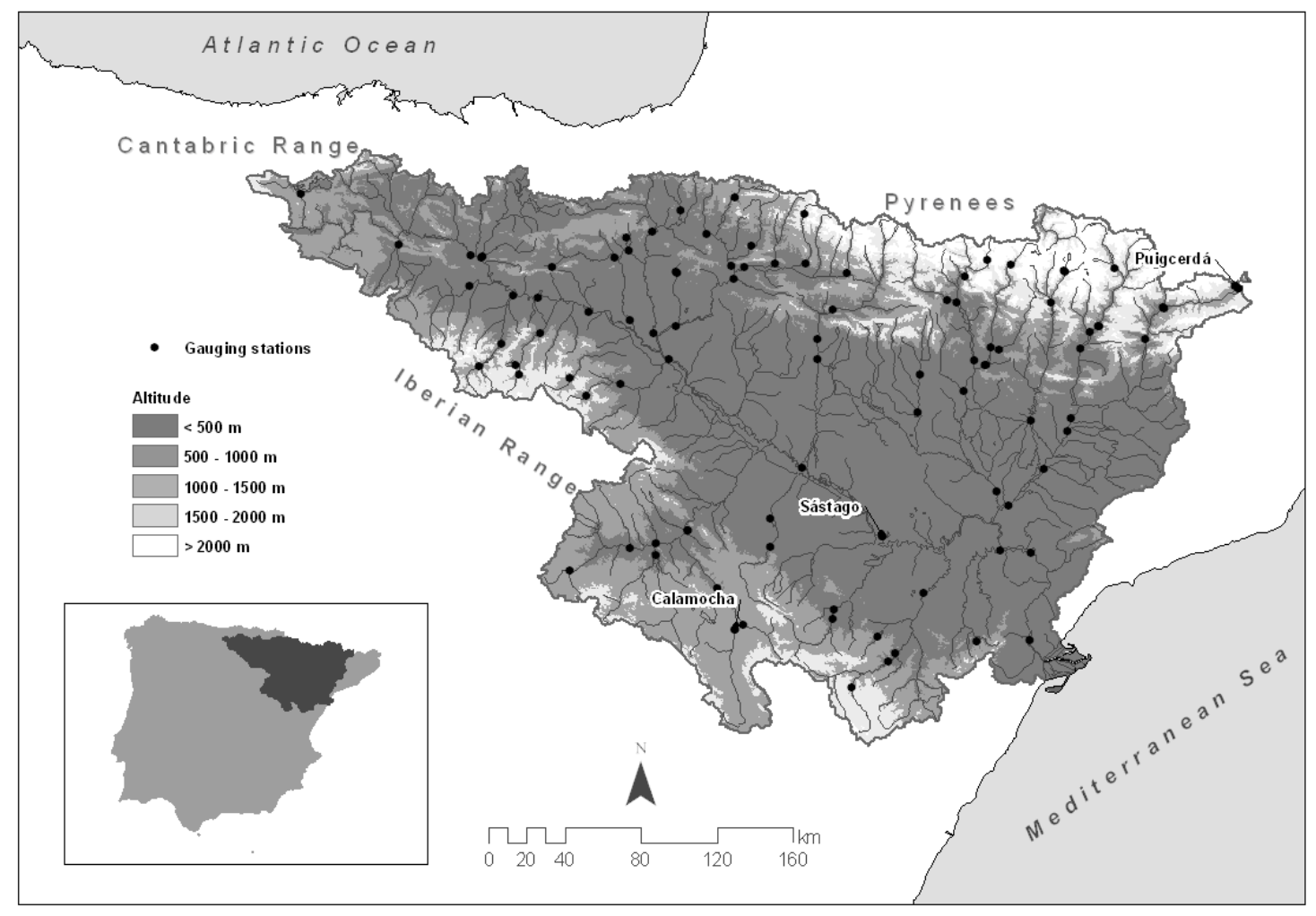

Figure 1. 

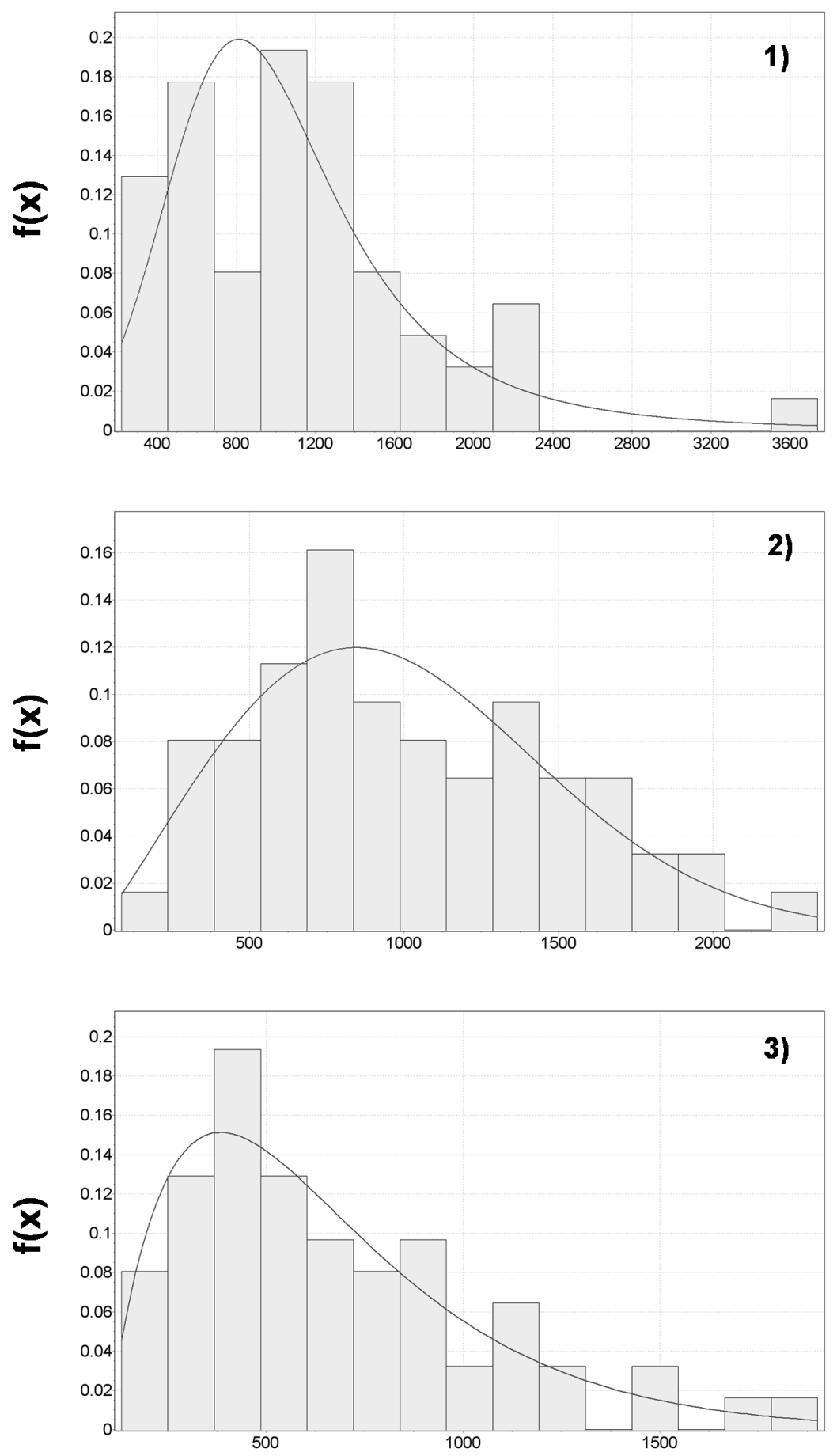

Figure 2. 


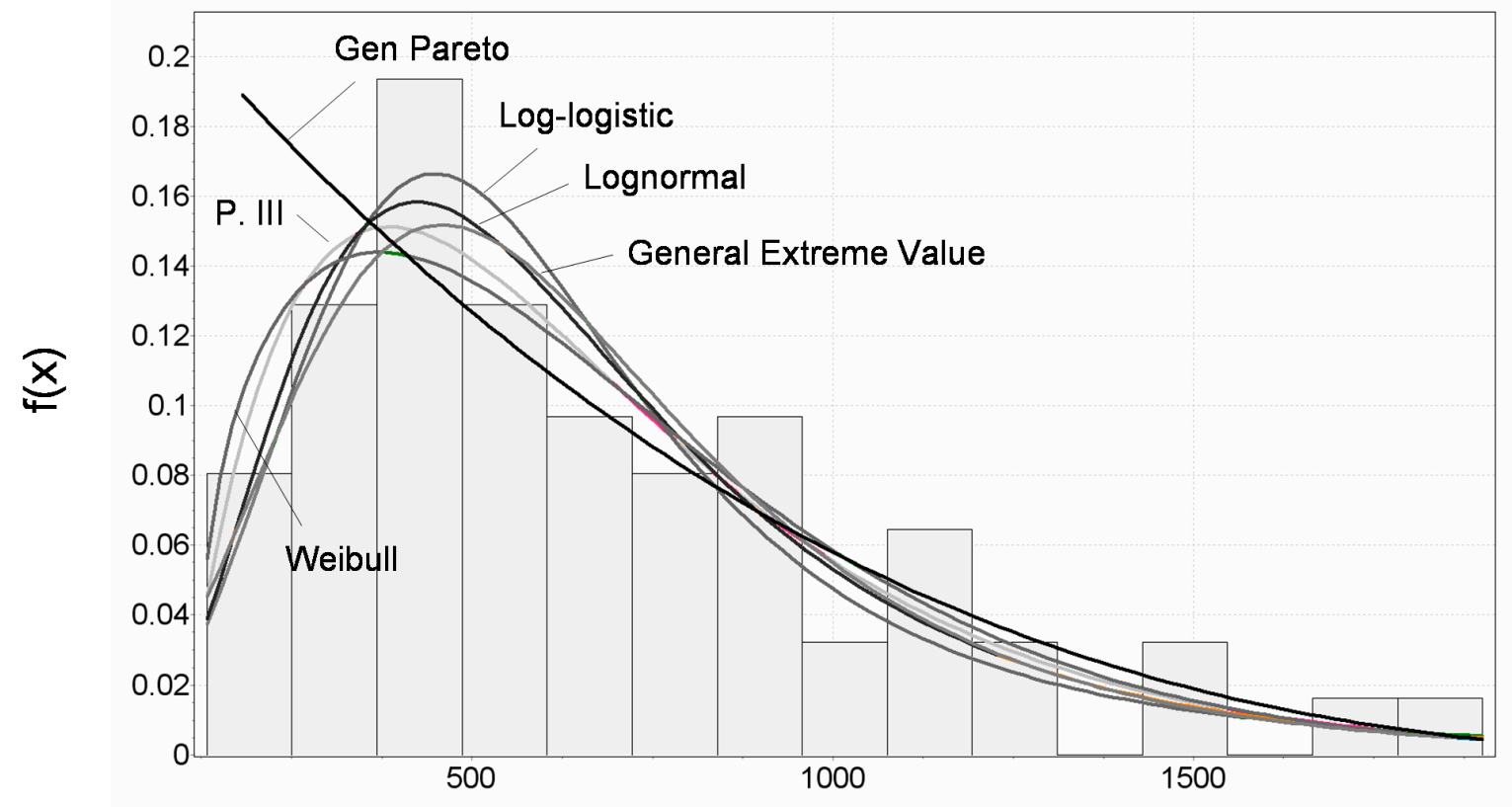

Figure 3. 


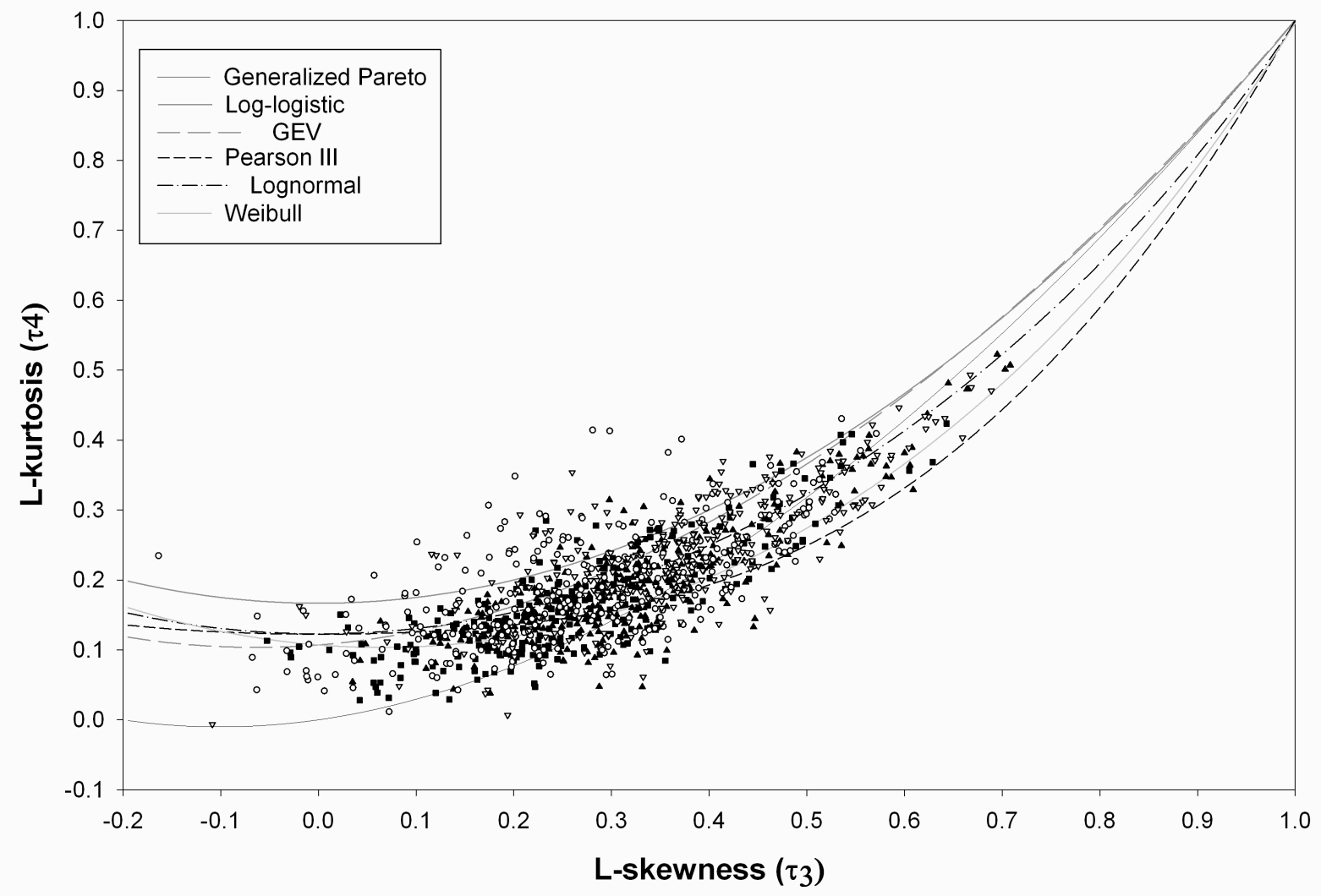

Figure 4. 


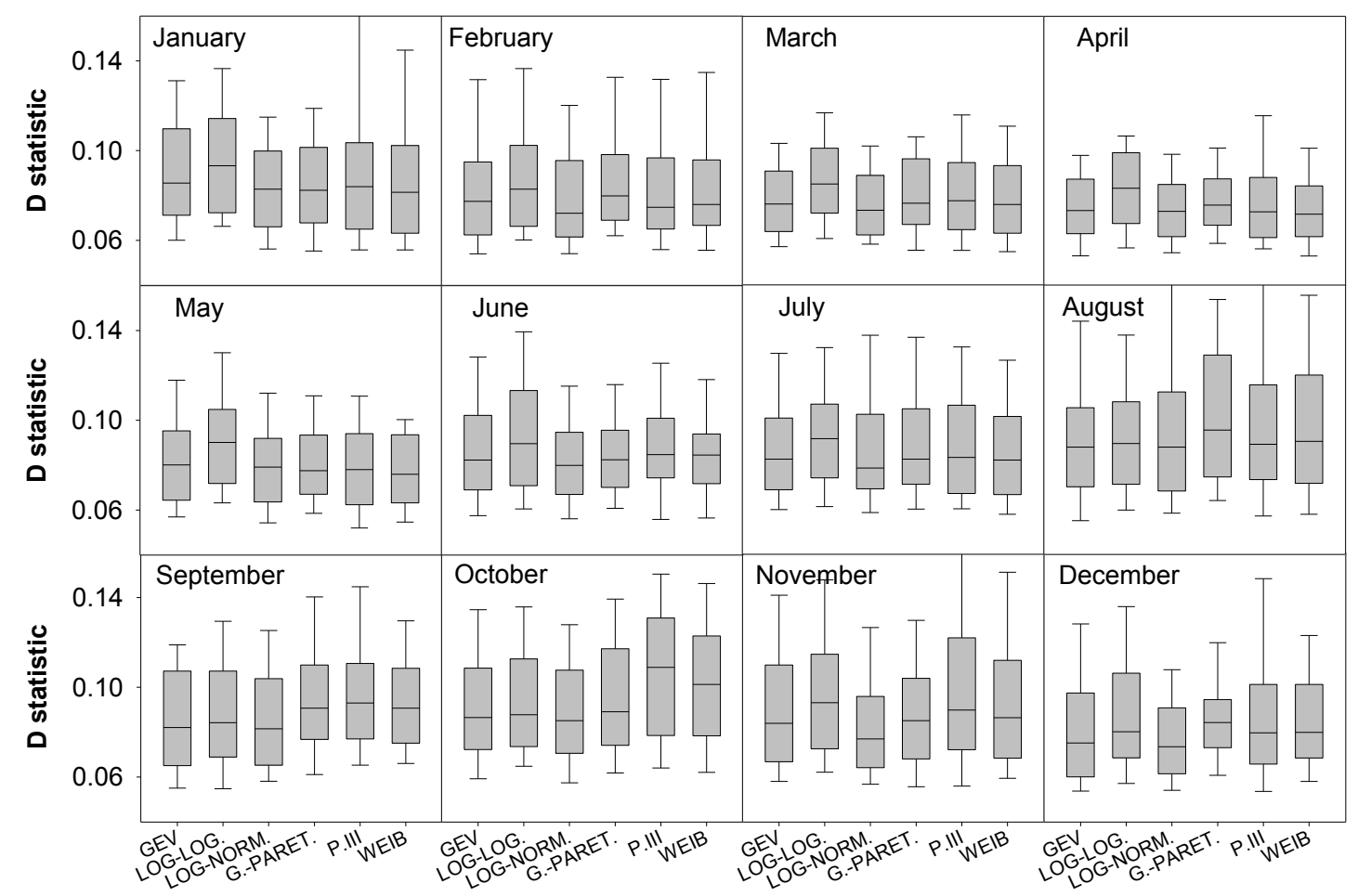

Figure 5. 


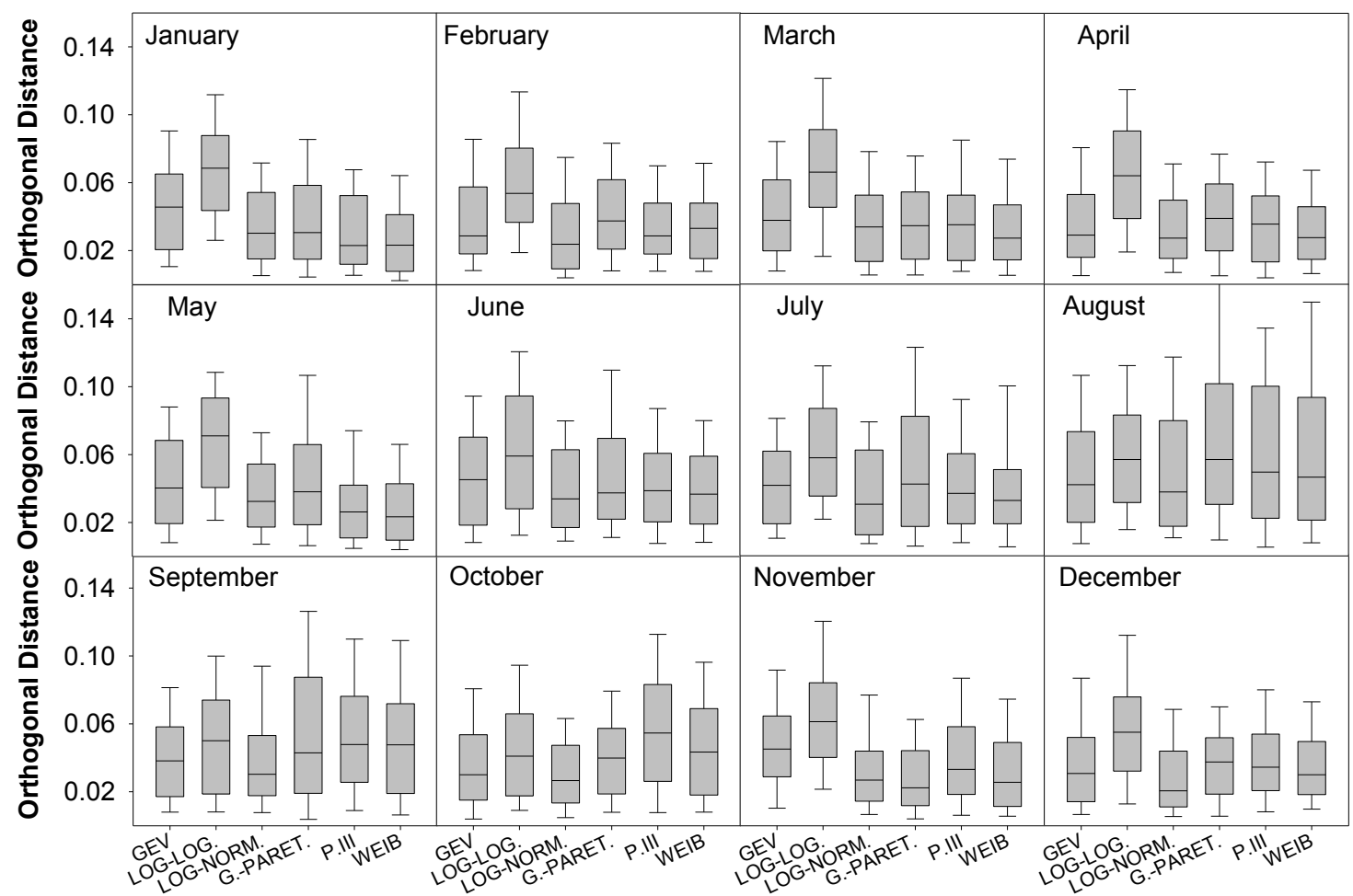

Figure 6 

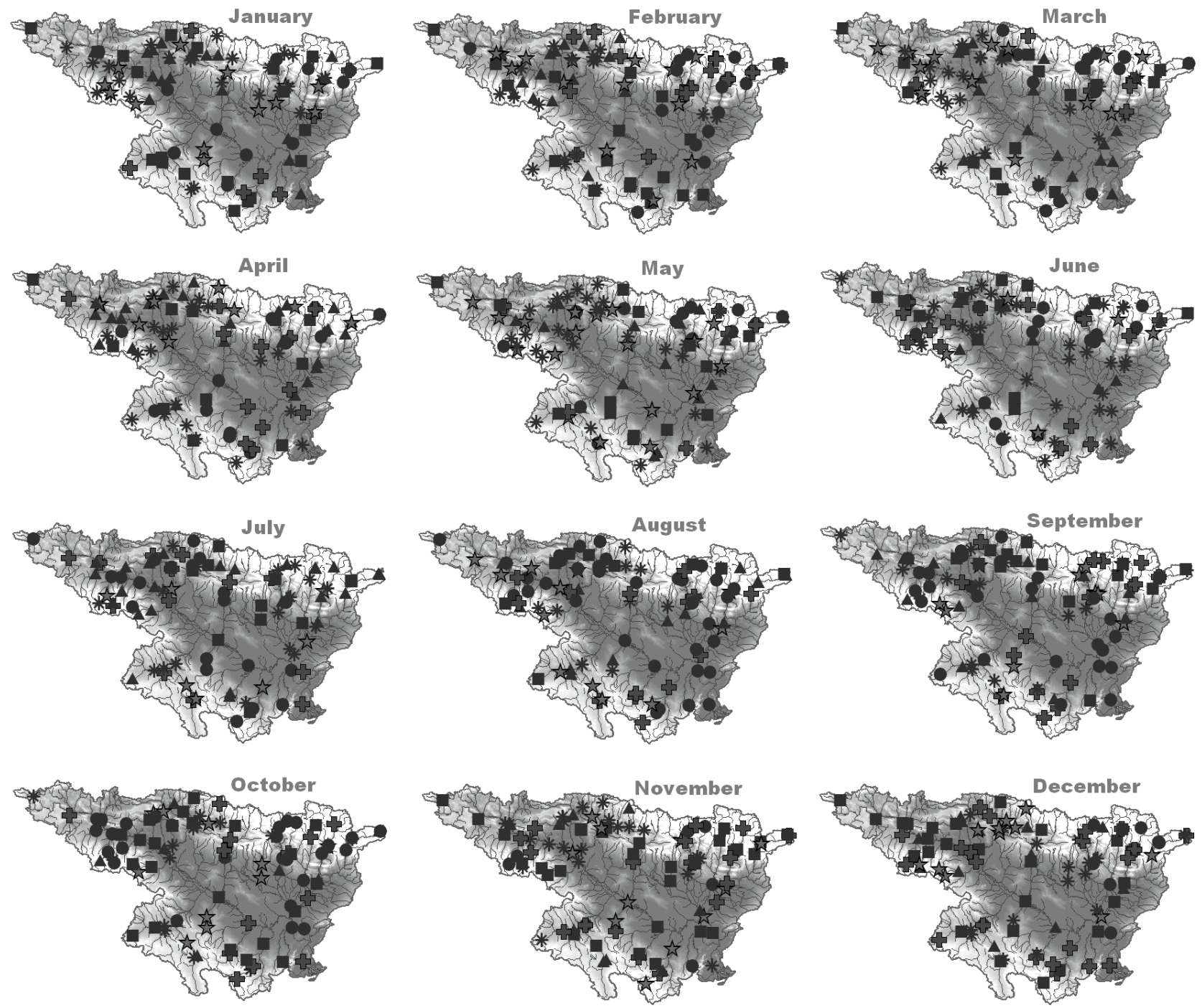

- LogNormal \& Generalized Extreme Value

- LogLogistic ^ Pearson III

^ Weibull * Generalized Pareto

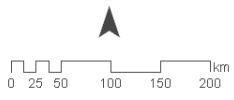

Figure 7. 

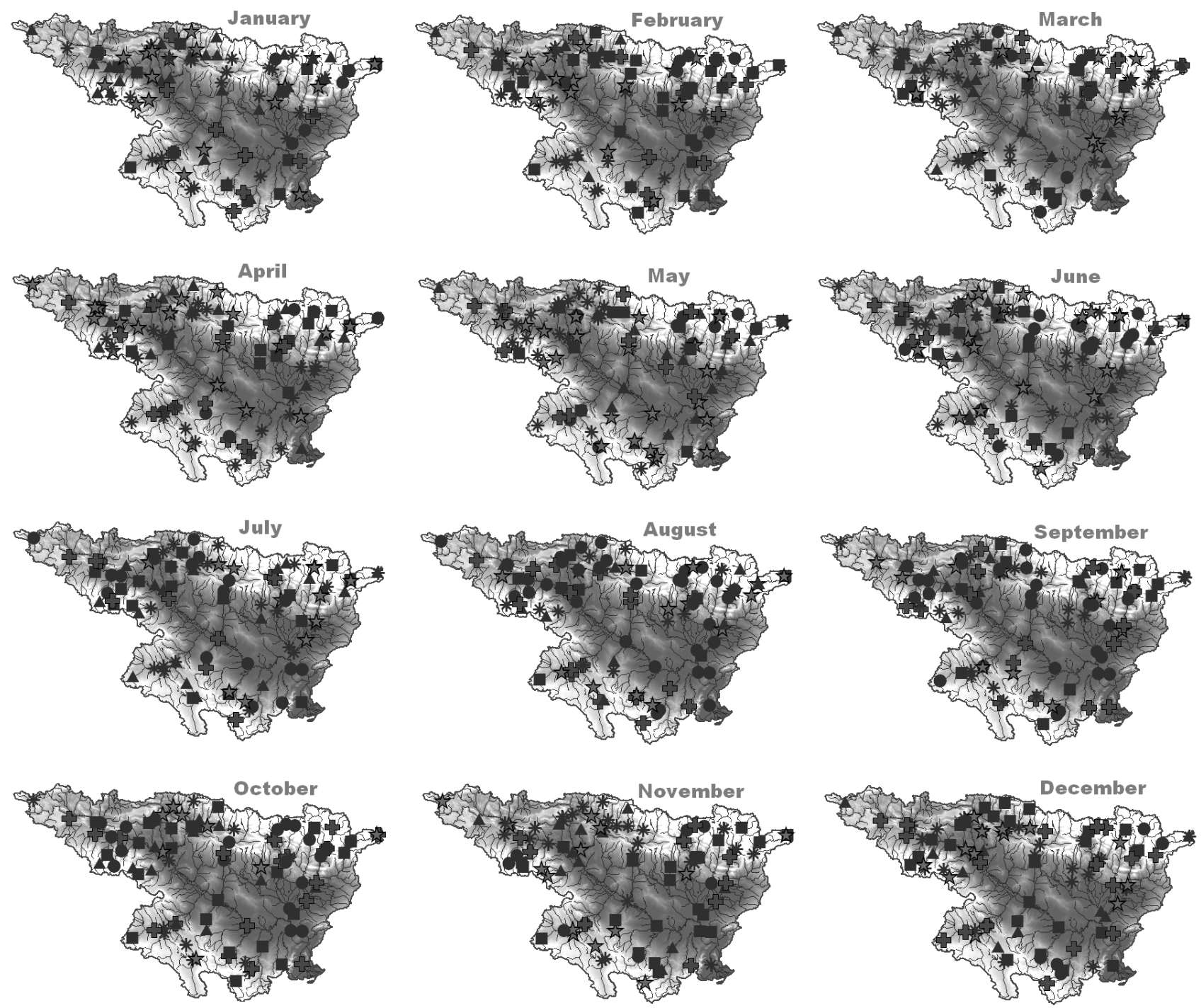
- LogNormal
4 Generalized Extreme Value
- LogLogistic
t Pearson III
A Weibull
* Generalized Pareto

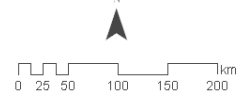

Figure 8 

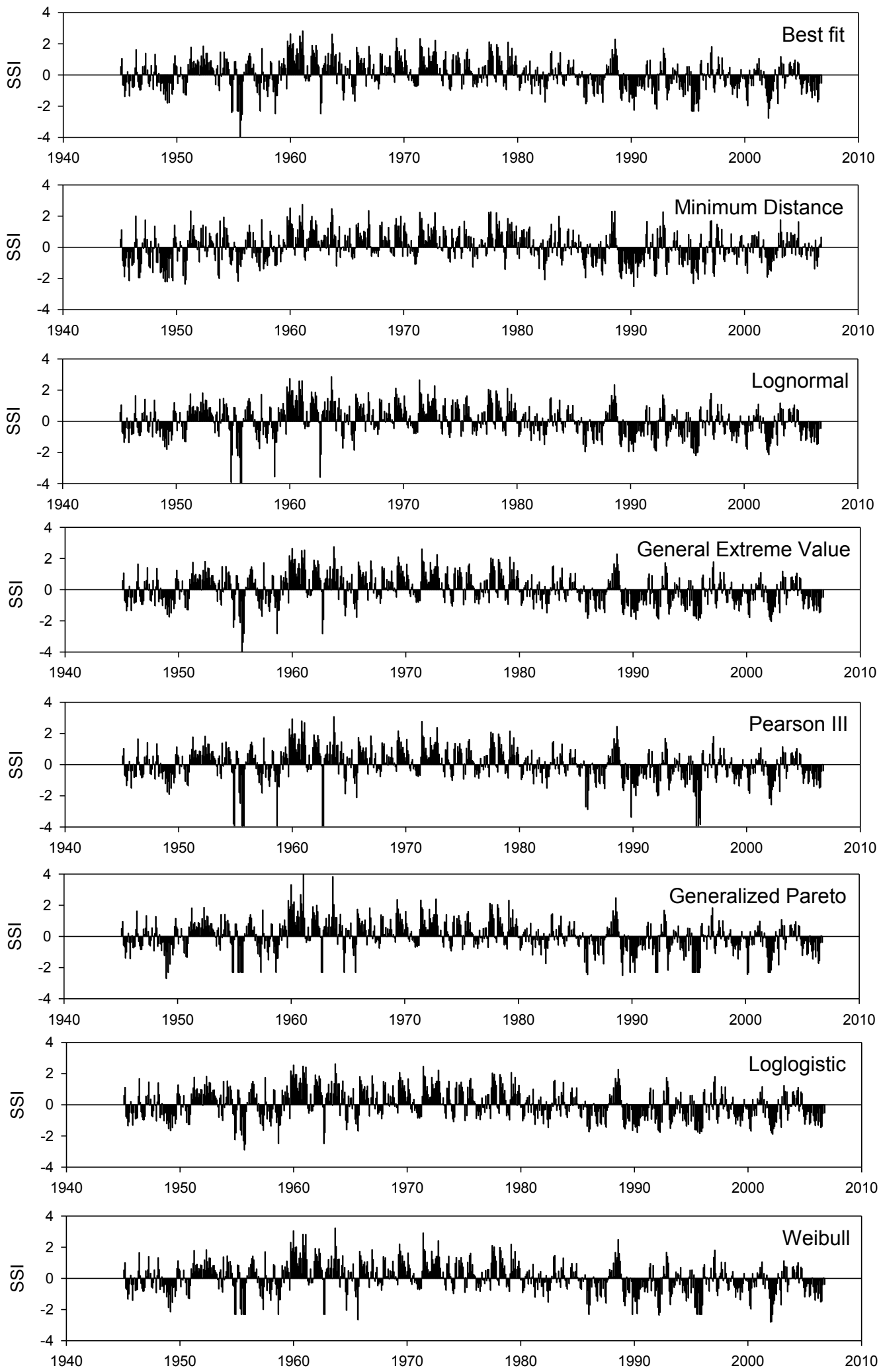

Figure 9. 

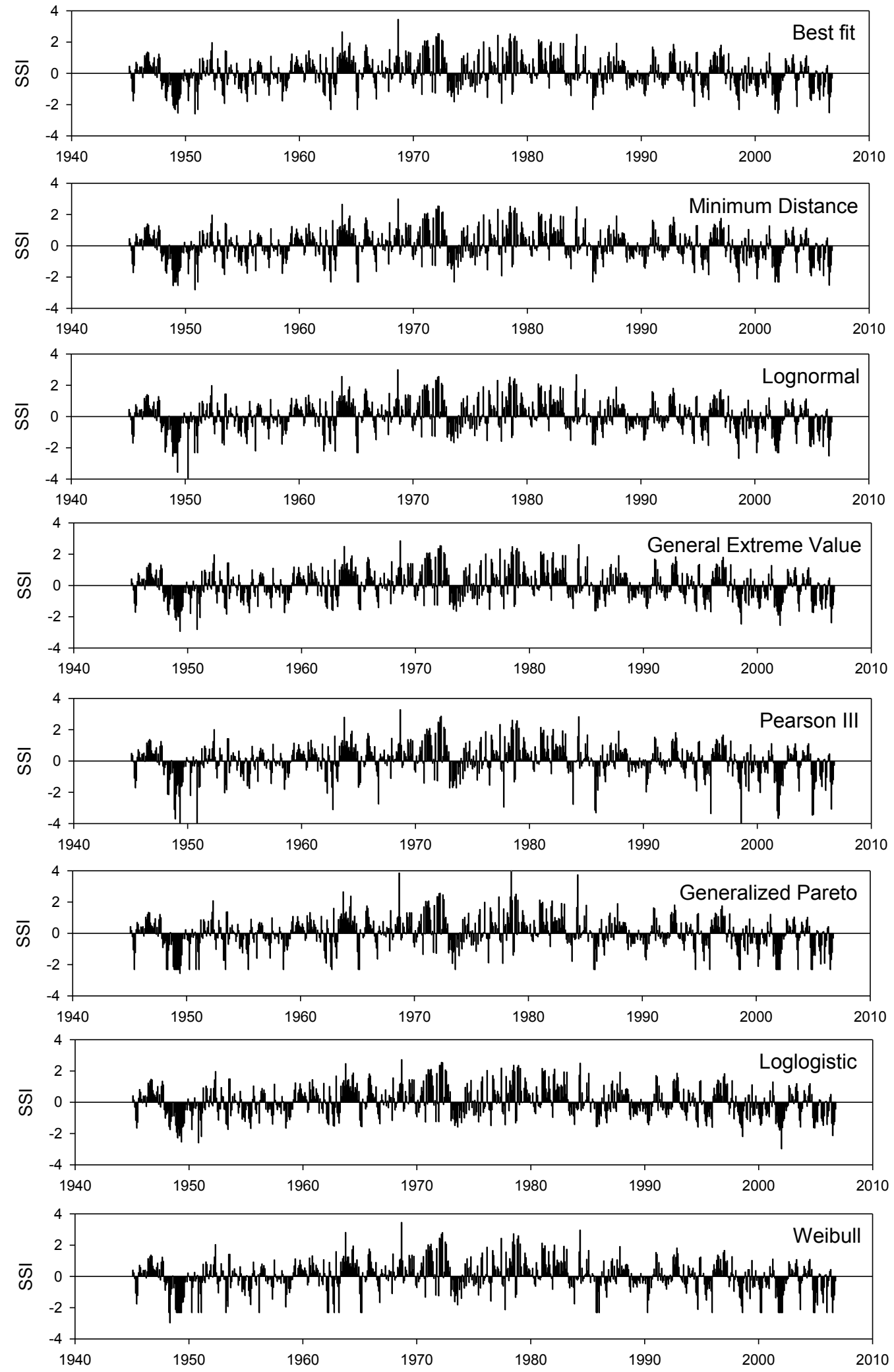

Figure 10. 

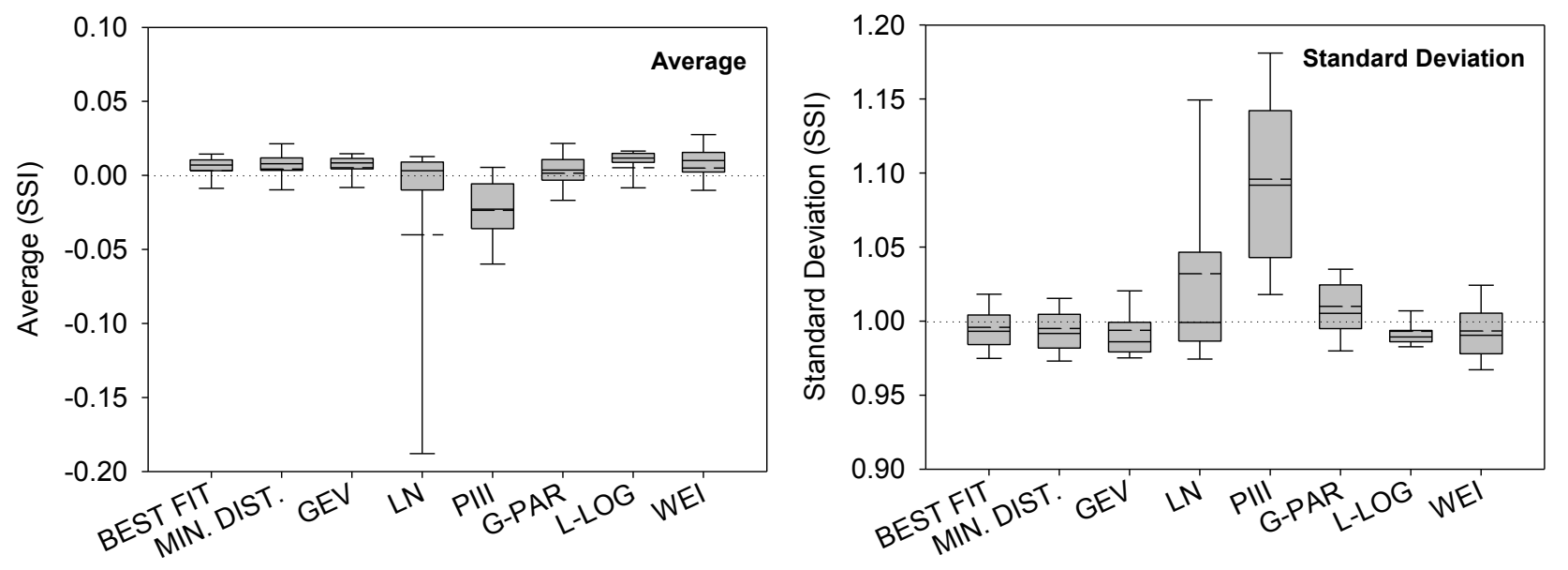

Figure 11. 

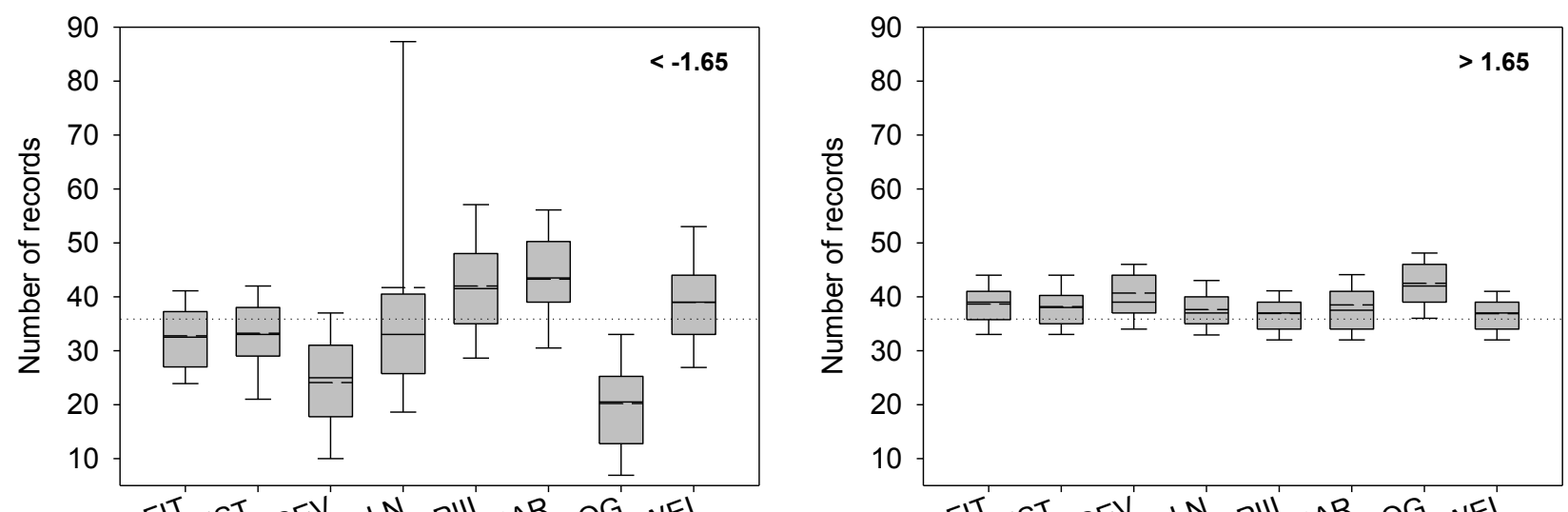

BESTFI'DIST. GEV LN PIIIGAPR LLOG WEI
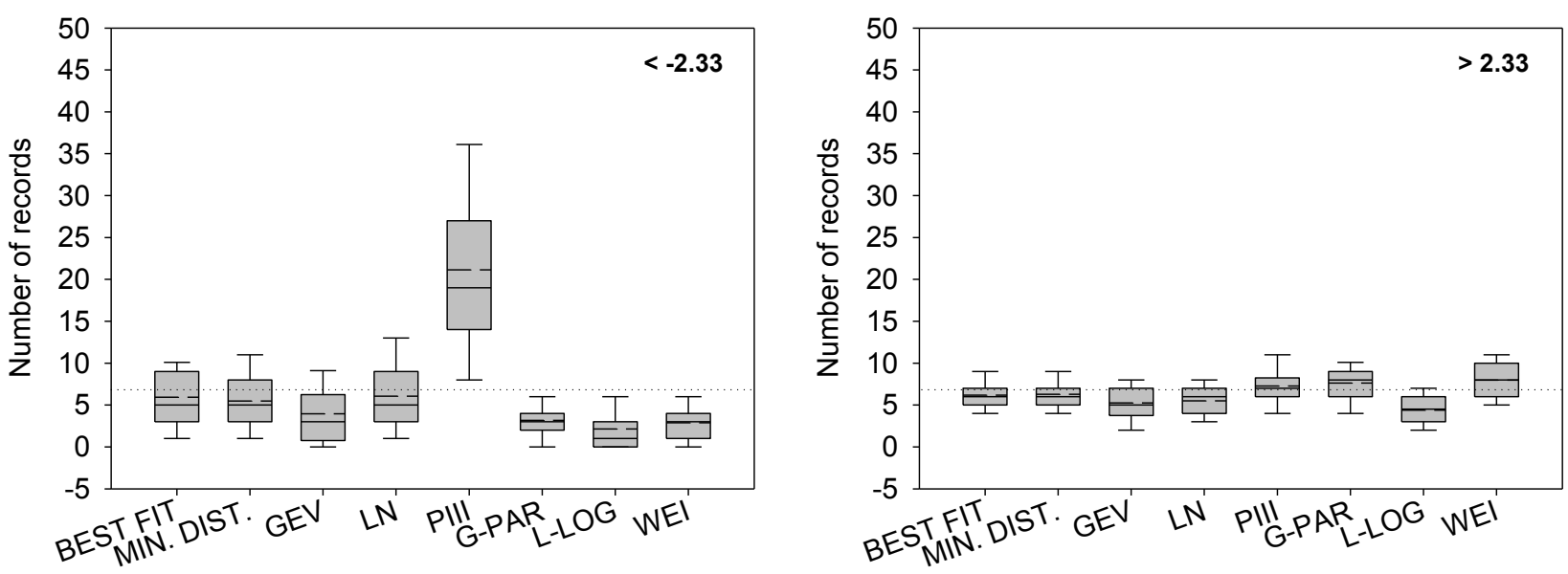

Figure 12. 